\title{
SEDIMENT DATING BY LUMINESCENCE: A REVIEW
}

\author{
J. R. PRESCOTT and G. B. ROBERTSON \\ Department of Physics and Mathematical Physics, University of Adelaide, South Australia 5005
}

\begin{abstract}
In the present article we review applications of luminescence methods for the determination of the age of sediments for Quaternary Earth science. "Sediment" is taken to include any mineral particles transported by wind, water and/or ice and subsequently deposited. Methodology is not discussed per se but appears in context. The emphasis is on recent work and is illustrative rather than exhaustive. Applications in archaeology are mentioned only briefly. Successful dating requires that the luminescence signal has been zeroed by sunlight at the time the sediment was laid down. Dune sands and loess transported in full daylight usually satisfy this condition and have been dated by both traditional thermoluminescence and by optical methods. Optical dating is advantageous for less well-bleached sediments, such as are found in colder climates and those laid down by fluvial and glacial processes, although the prospects for dating the latter are shown to be poor. Among less common contexts are volcanic eruptions, earthquake faults and tsunami deposits. The dating of very young sediments, less than $2 \mathrm{ka}$, is demonstrated and the factors limiting the dating of very old sediments, $500 \mathrm{ka}$ to $1 \mathrm{Ma}$, are discussed. Validation of any dating method by comparison with other methods is necessary; luminescence ages have been successfully compared with ages obtained by, for example, ${ }^{14} \mathrm{C}$, $\mathrm{U}-\mathrm{Th}$ series and $\delta^{18} \mathrm{O}$ isotope ratios. The most difficult problems encountered in dating quartz, feldspars and undifferentiated fine grain mixtures include: anomalous fading (which leads to underestimates of age), incomplete zeroing (which gives overestimates) and sample inhomogeneity. Methods devised to minimise these effects include preheating regimes, selection of observing wavelengths and of stimulating wavelengths for optical dating, the use of single aliquot and single grain measurements. The use of appropriate data analysis procedures is also important. Advice on current best practice on procedures for obtaining reliable ages is offered and, in all applications, there are suggestions as to where further research might be directed.

(C) 1998 Elsevier Science Ltd. All rights reserved
\end{abstract}

\section{INTRODUCTION-THE SCOPE OF THE TOPIC}

Double, double toil and trouble;

Fire burn and cauldron bubble...

[Shakespeare W. (1606) Macbeth. Act 4, Scene 1.]

Readers of Shakespeare will recognise the context of the quotation at the head of this article: The Witches are engaged in a ritual which is designed to help them predict the future. Practitioners of luminescence dating share something in common with the Weird Sisters - except that we are trying to predict the past. While we have the advantage of science-based know-how, the quotation reminds us that some of the approaches to the methodology of luminescence dating have had affinities with this passage from Macbeth: the ingredients have not all been selected with full scientific rigour.

Nevertheless, the application of luminescence dating to sediments is flourishing and, given judicious choice of methodology, can produce credible ages in a wide variety of contexts. It is the aim of this article to illustrate the possibilities, voice some reservations and point the way to where new work is required.

This article covers what is now the largest application of luminescence dating, certainly in variety and probably in absolute number of determinations, if we exclude the application to authenticity. We have taken sediments to include any mineral particles transported by wind and/or water and subsequently deposited. A few examples of the use of sediment dating to find the age of something else are also included. Since methodology is discussed in a separate article (Wintle, this volume) this will be assumed and discussion will centre on particular issues as they arise, recognising that this implies prior or concurrent reading.

Luminescence dating began with thermoluminescence (TL) and was developed initially to find the age of pottery. By extension it has been used for materials that had been heated directly, such as tephra, and to find the ages of lava flows from heated underlying sediments.

The key step that led to the extension of luminescence dating to sediments was the recognition that exposure to photons in sunlight during transport had the capacity to optically reset the luminescence clock, in the same way that heating resets it (Shelkoplyas and Morozov, 1965).

An independent but related step was the recognition by Huntley that emission of light could be stimulated by optical means, and this has led to the development of optical dating methods (Huntley et al., 1985). Typically, irradiation at $\sim 500 \mathrm{~nm} / 2.5 \mathrm{eV}$ leads to emission at wavelengths shorter than 
$400 \mathrm{~nm} / 3.1 \mathrm{eV}$ which can be isolated from the stimulating wavelength by optical filters. This is commonly known as OSL (optically stimulated luminescence). Hütt et al. (1988) extended the range of stimulating wavelengths into the infrared (IRSL).

Technically, all optical stimulation should be described as "optical", regardless of photon energy/ wavelength, but usage has hallowed the separate use of the terms OSL and IRSL. We shall use "OSL" where a general reference is called for and more specific terminology, e.g. GLSL (green light stimulated luminescence), where the occasion requires. In passing, we shall usually quote both wavelength and photon energy, the latter being in better accord with the physics of the processes involved.

The first suggestion that sunlight would reset the TL of sediments, which could thus be dated by TL, appears to have come from Shelkoplyas and Morozov (1965) in the former USSR. This and other early Soviet work is reviewed by Dreimanis et al. (1978) who conclude that the Soviet work appears to have achieved satisfactory relative ages but not absolute ages. The lack of this work in readily accessible Russian sources or in translation makes it difficult to be sure, but we tend to agree with this judgement. However, this work did not become known outside the USSR until after Wintle and Huntley $(1979,1982)$ had recognised the possibility and developed practical methods for its use.

A number of reviews dealing with the application of luminescence methods to the dating of sediments has appeared in the past year or so; and others are known to be in preparation. For this reason, the present article will not attempt to be exhaustive. Reviews are listed under that heading in Appendix A. The most recent are those of Wintle (1994), Berger (1995) and Duller (1996b). In general we shall not attempt to repeat the coverage of these three reviews. Rather, we shall comment on a few issues of most recent current interest, in the context of what is possible, with some analysis of limitations.

Most applications are in age determinations for Quaternary Earth science. Applications in archaeology are dealt with in a separate article (Roberts, this volume). In fact, as we have often pointed out, in the field of sediment dating any answer to a question posed by an archaeologist is likely to also be of interest to a Quaternary Earth scientist. This is particularly true for the more ancient Quaternary landscapes found in Australia or Africa.

The reference list makes no claim to be exhaustive. For a comprehensive current-awareness coverage of all aspects of luminescence dating, including its scientific base, applications, and articles in which age determinations are included, we commend the Bibliographies compiled by Wintle and published in Ancient $T L$ from time to time.
Luminescence dating has already been applied to a remarkable range of sediments. We have divided this paper into the following sections:

1. Introduction - the scope of the topic

2. Tests, comparisons and validation

3. Wind-blown dunes and similar associations

4. Loess

5. Water-laid deposits

6. Icy environments

7. Tephra and other heated materials

8. Some imaginative applications

9. How old and how young?

10. Perspectives, problems and prospects

\section{TESTS, COMPARISONS AND VALIDATION}

In testing a new dating method, validation against independent ages is a necessary step. Further, in dating a given site the value of ages obtained by any dating method is enhanced by parallel measurements with a different method or methods. Sites where this is possible are to be valued for the comparison itself, either as a check on the age or as a test of methodology. Since luminescence dating is one of a number of methods and, since new procedures call for validation and comparison, we start by discussing some examples of each.

\subsection{Luminescence dating and ${ }^{14} \mathrm{C}$ dating}

Luminescence dating complements ${ }^{14} \mathrm{C}$ dating in the whole age range over which the latter can be used: in practice, to around $40 \mathrm{ka}$. Whether we in the luminescence dating community like it or not, ${ }^{14} \mathrm{C}$ dating is so well established that it seems to be automatically assumed that any disagreement between it and luminescence dating must be resolved in favour of the former. In the experience of the authors this is particularly true of the archaeological community, but much less so among Quaternary Earth scientists. In fact there is abundant evidence, particularly from Europe, that agreement between the two modalities is good to excellent up to about $15 \mathrm{ka}$. Examples are to be found in Smith et al. (1990), Selsing and Mejdahl (1994) and Stokes and Gaylord (1993). An example of a profile which compares OSL and ${ }^{14} \mathrm{C}$ ages from this last reference is shown in Fig. 1. It is coincidental that $15 \mathrm{ka}$ corresponds to the limit of calibrated ${ }^{14} \mathrm{C}$ ages. It is for the transition region beyond this that comparisons are particularly valuable and not very common.

One compendium of TL vs. uncalibrated ${ }^{14} \mathrm{C}$ comparisons for ages exceeding $10 \mathrm{ka}$ appears in Smith et al. (1997). An updated version of their data is shown in Fig. 2. It would be "conventional" 


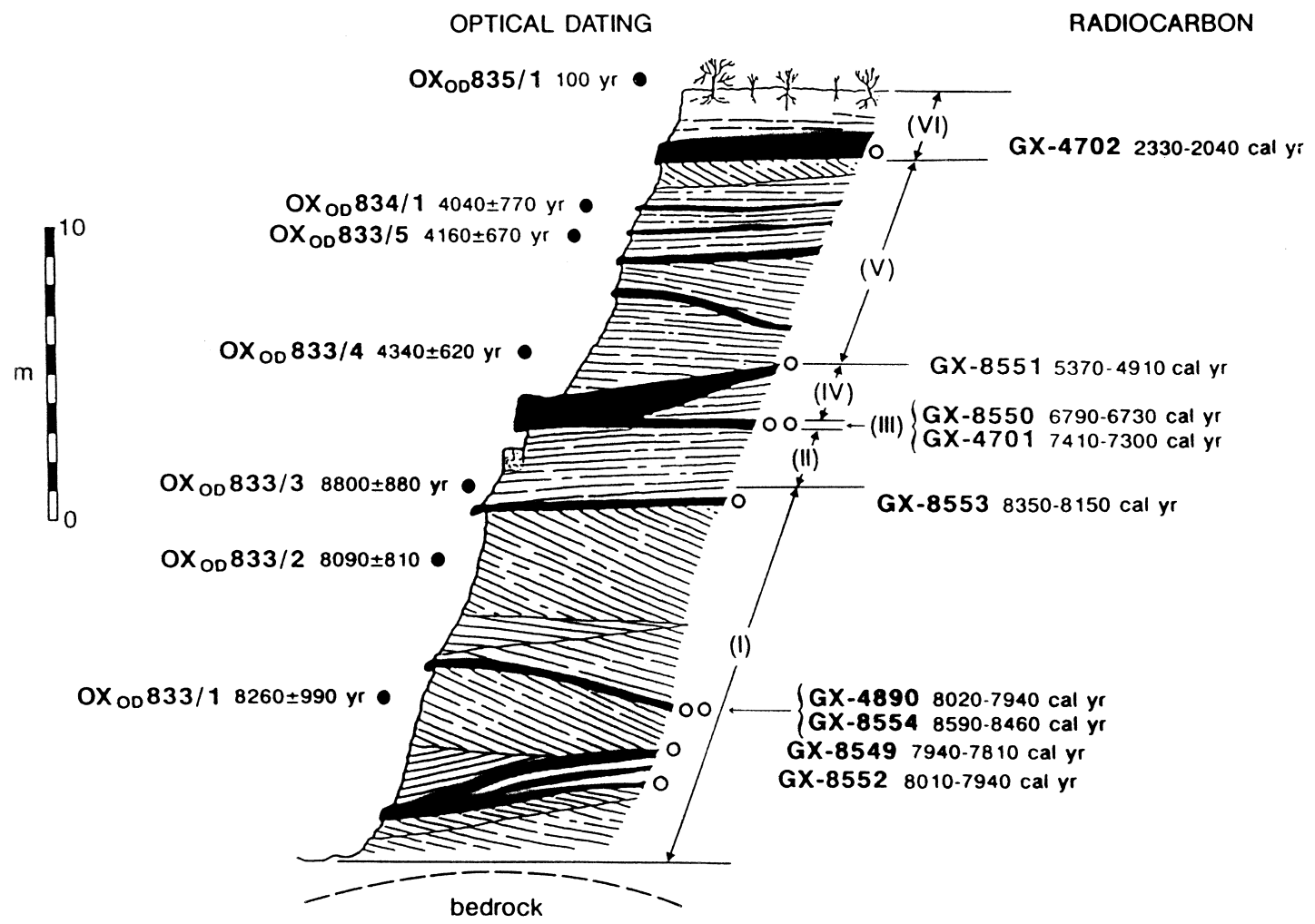

Fig. 1. Schematic diagram showing comparative ${ }^{14} \mathrm{C}$ and OSL ages in a section for the Holocene deposits at Clear Creek, Wyoming. Black lenses are interdune deposits (after Stokes and Gaylord, 1993).

wisdom to attribute the whole of the uncertainty in this comparison to the luminescence measurements, but it is open to the interpretation that the uncertainty in ${ }^{14} \mathrm{C}$ is comparable and considerably exceeds the counting errors in the determination of the latter.

The fact that the TL ages in Fig. 2 are significantly larger than the ${ }^{14} \mathrm{C}$ ages is an expression of the long-term variability in the ${ }^{14} \mathrm{C}$ content of the Earth's atmosphere, as a consequence of variations in cosmic ray intensity. The broken line shows the predicted trend based on known variations in the Earth's magnetic dipole moment, which determines the cosmic ray intensity in the atmosphere (Laj et al., 1996). A subset of the same data, with relevant discussion, is quoted by Taylor et al. (1996).

It is worth noting that Bell (1978) was probably the first to show that $\mathrm{TL}$ and ${ }^{14} \mathrm{C}$ ages were not the same at $\sim 30 \mathrm{ka}$, although it was not published until 1991 (Bell, 1991). Huxtable and Aitken (1977), on the basis of TL ages from the same site, commented that such a difference was possible but that the uncertainty in their results did not permit a definite conclusion.

A recent comparison (David et al., 1997) of a pair of OSL ages with a suite of $21{ }^{14} \mathrm{C}$ ages, all from the same stratigraphic level in the Ngarrabullgan Cave, Queensland, yields an OSL age of $34.7 \pm 2.1 \mathrm{ka}$ to be compared with a mean ${ }^{14} \mathrm{C}$ age of $32.5 \pm 1.2 \mathrm{ka}$ (two outliers excluded). In this case the samples have been collected with such a comparison specifically in mind and they are quite unusual in that there are enough ${ }^{14} \mathrm{C}$ ages to plot a distribution and to quote a standard deviation.

Large sets of luminescence ages from the same stratigraphic level, from which a measure of reproducibility of luminescence dating per se can be derived, do not appear to exist. This would appear to be a worthwhile research topic.

A surprising number of the sites to be discussed in Sections 3-5 have overlapping luminescence and ${ }^{14} \mathrm{C}$ ages but it is vexing to a reviewer that these rarely come from the same stratigraphic level or appear to be dating the same events. It would seem a good idea to structure sample collection in such a way as to ensure useful comparisons among different methods.

Not all luminescence vs. ${ }^{14} \mathrm{C}$ comparisons turn out as expected. Smith et al. (1997) describe work at the Puritjarra rock shelter in the Northern Territory, Australia. Luminescence ages were found for $100 \mu \mathrm{m}$ quartz by total bleach, selective bleach and GLSL. Ages by ${ }^{14} \mathrm{C}$ included both conventional and AMS determinations. In a suite of $31{ }^{14} \mathrm{C}$ and 23 comparable luminescence ages, covering zero to $35 \mathrm{ka}$, the latter ages were high for all but two samples. This is a rock shelter site and it is suggested that the sediment contains a small percentage of unbleached quartz from in situ breakdown 


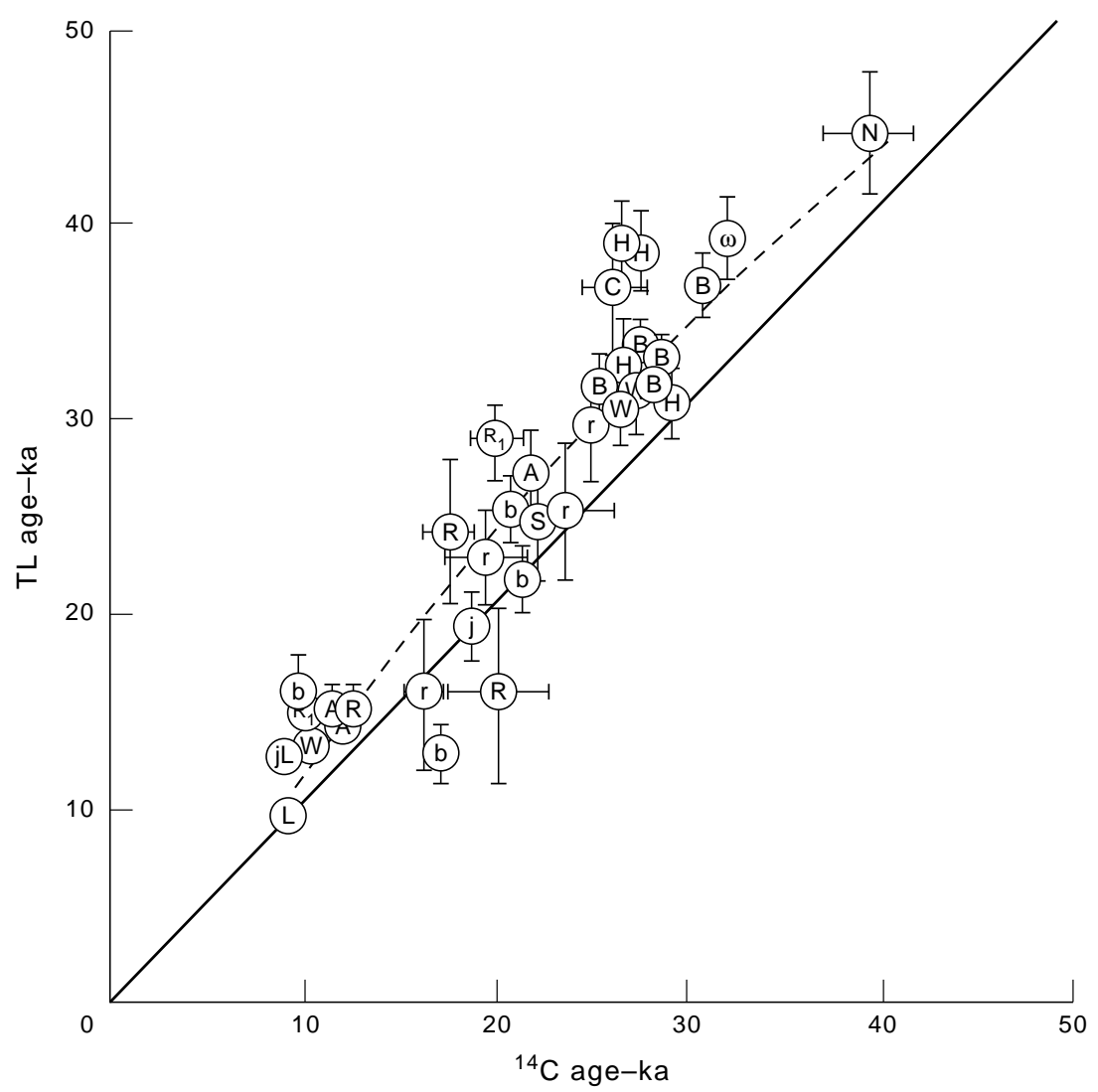

Fig. 2. Compendium of TL and uncalibrated ${ }^{14} \mathrm{C}$ ages greater than $\sim 10 \mathrm{ka}$. These data are updated from Smith et al. (1997). The solid line is the 1:1 age correspondence; the broken line shows the expected values of ${ }^{14} \mathrm{C}$ ages, based on changes in the Earth's ${ }^{14} \mathrm{C}$ budget arising from changes in the Earth's magnetic field. The sources of the data are indicated by letters on the figures, as follows: A: Aitken (1987) B: Bell (1991) b: Berger et al. (1984) C: Chawla et al. (1992) H: Huxtable and Aitken (1977) j: Juvigne and Wintle (1988) L: Lundqvist and Mejdahl (1987) N: Nanson and Young (1987) r: Readhead (1988) R: Roberts et al. (1990) R1: Roberts et al. (1994) S: Shepherd and Price (1990) W: Wintle (1987) w: Wintle and Packman (1988).

of rock pieces from the shelter wall. The significance of this possibility for archaeological sites is discussed by Roberts (this volume).

\subsection{Comparisons among several dating methods}

Beyond the "40 ka limit" to ${ }^{14} \mathrm{C}$, luminescence dating provides an extension into the late Quaternary and a bridge to the early Quaternary, where methods based on radioactive decay $(\mathrm{K} / \mathrm{Ar}$, U-series, fission track) can be applied for comparison, at least in principle. However, there is a paucity of such comparisons and the work of Nanson et al. (1991) illustrates some of the difficulties in making them.

In the time range $10-30 \mathrm{ka}$, Abeyratne et al. (1997) give a very comprehensive comparison of dating methods, based on the Batadomba cave site in Sri Lanka. Ages are reported on ${ }^{14} \mathrm{C}$ for shells and charcoal, ESR, TL and OSL (using quartz) for the age range $10-30 \mathrm{ka}$. While these are technically archaeological sites, TL and OSL are based on sediments and are mentioned here in that context.
Specifically: TL, ESR on shells and ${ }^{14} \mathrm{C}$ ages mostly agree within the measurement errors, but the OSL ages appear to be systematically lower. The latter may well be due to fading, a subject to which we shall return. The comparison is shown in Fig. 3.

Sherwood et al. (1994) contains an intercomparison of $\mathrm{TL},{ }^{14} \mathrm{C}$, amino acid racemisation, U-Th series and ESR, covering the present to about $300 \mathrm{ka}$. Unfortunately, not all methods were applied to all sites in what was a regional survey, and the comparisons involving luminescence are limited, but it represents an unusually wide-ranging comparison.

In a substantial compilation of published work from a variety of sources, with additional material added, Pillans et al. (1996) compare fission track, $\mathrm{K} / \mathrm{Ar}$, Ar/Ar and TL and IRSL ages with the age of the Rangitawa Tephra time-marker in New Zealand. This is securely dated in ocean cores at $340 \pm 7 \mathrm{ka}$ by comparison with the oxygen isotope record. Such a time-marker, independently dated on geological evidence, is a very desirable validation feature. 
(a)

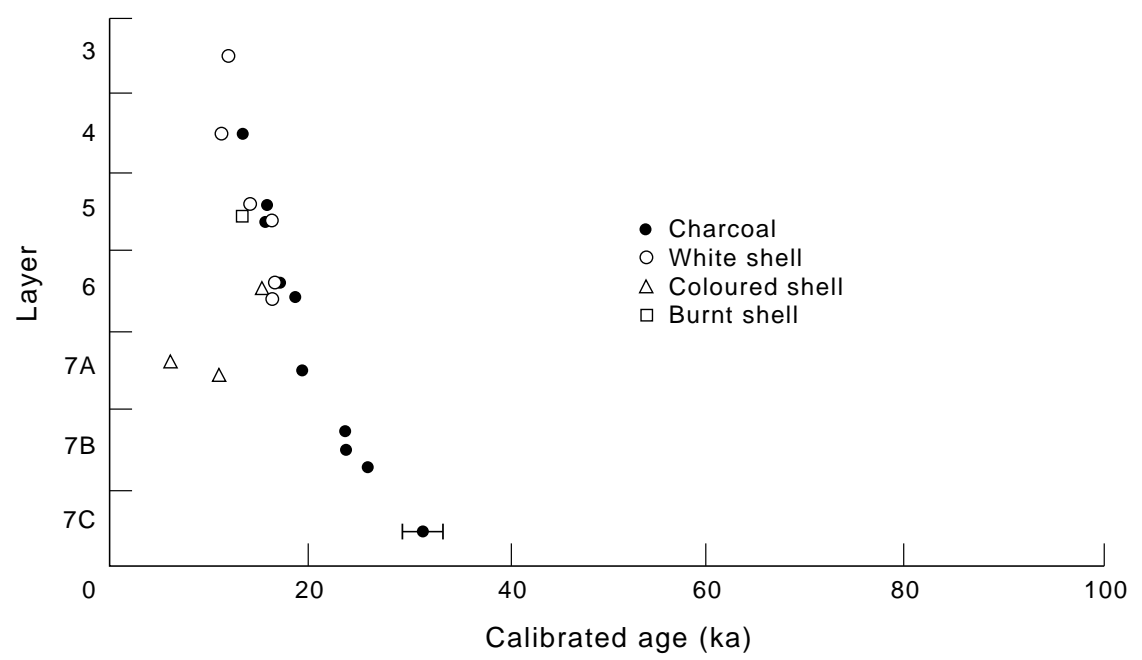

(b)

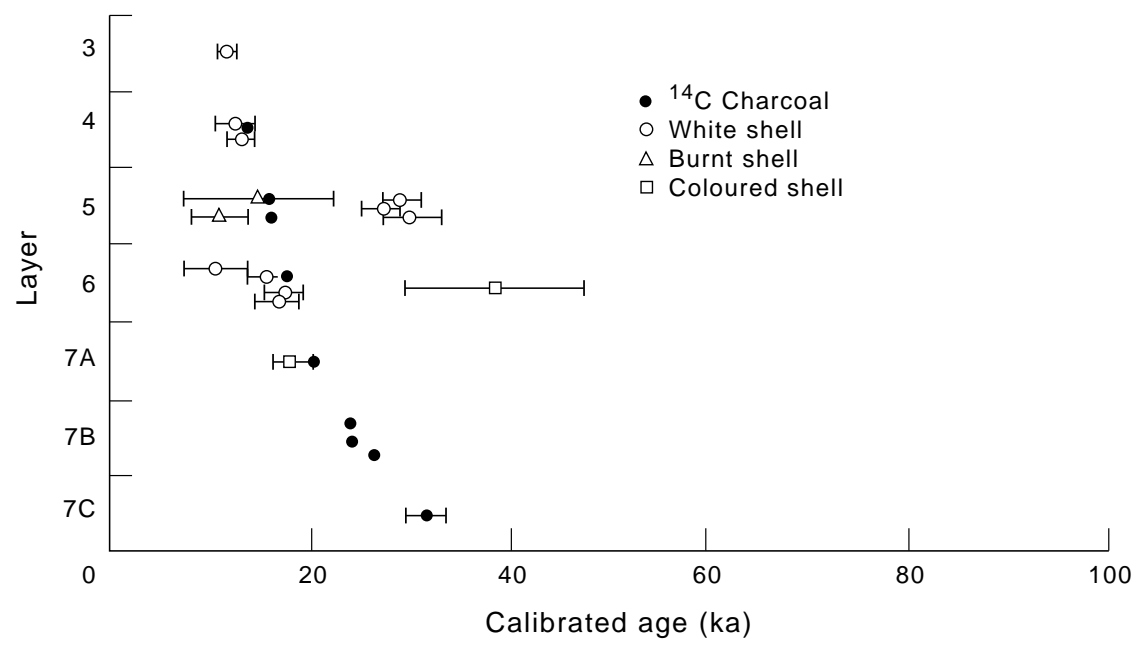

(c)

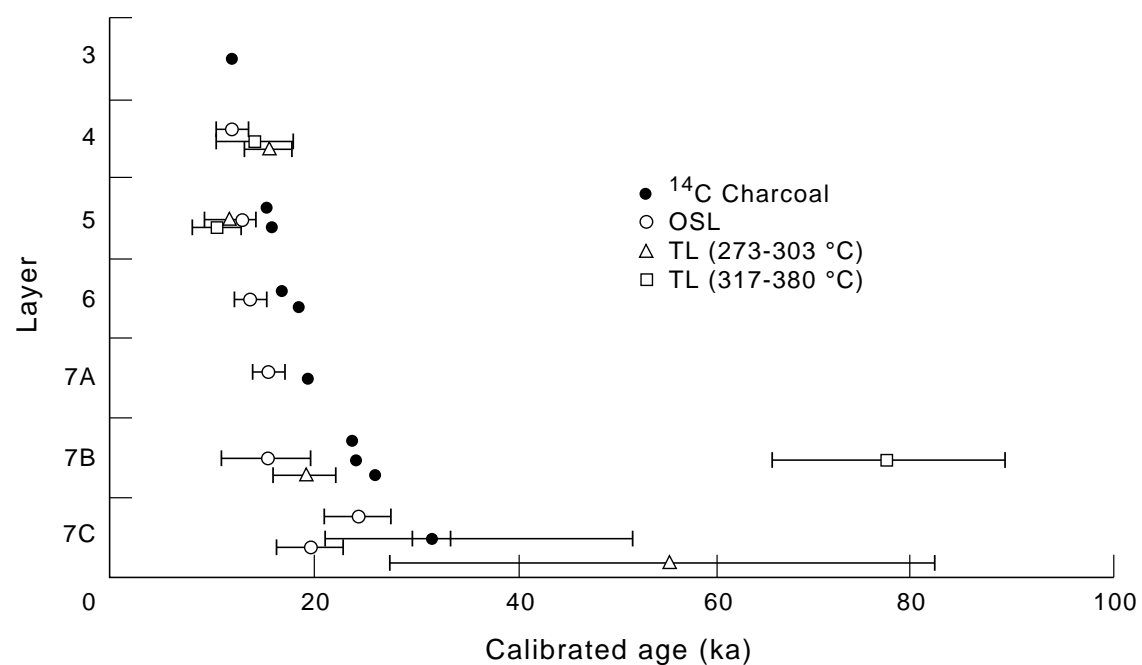

Fig. 3. Comparison of ages for the Batadomba Cave, Sri Lanka, by differing methods and for differing samples, as indicated in the body of the figures. The vertical scale is not linear. The numbers are identification for the excavation layers: layer 5 is at $\sim 1.8 \mathrm{~m}$ from the surface and the bottom of layer $7 \mathrm{C}$ is at $\sim 2.5 \mathrm{~m}$. Calibrated ${ }^{14} \mathrm{C}$ ages based on charcoal are common to all figures. (a) Calibrated radiocarbon results, (b) ESR on shells compared with ${ }^{14} \mathrm{C}$, (c) OSL and TL compared with ${ }^{14} \mathrm{C}$ (after Abeyratne et al., 1997). 
The authors note that the methodologies for 15 TL and 4 IRSL ages were under experimental test. For loess closely above and below the tephra, observed luminescence ages range from 173 to $403 \mathrm{ka}$, within-sample uncertainties being of the order of $15 \%$. From a diagnostic point of view, however, TL using blue emission gave three ages consistent with the tephra ages, whereas use of ultraviolet emissions gave an average age of $300 \mathrm{ka}$ with a large statistical scatter. For a feldspar dune sand at two sites, 0.6 and $1.5 \mathrm{~m}$ above the tephra, TL and IRSL give ages of the order of $240 \mathrm{ka}$. These are significantly less than the tephra age and Pillans et al. attribute this to long-term fading.

It is interesting that only 15 of 51 diverse ages for the NON-luminescence dating methods were considered to be reliable. There is perhaps a general warning here for luminescence practitioners.

Duller (1994a) found that OSL and IRSL for ages for New Zealand feldspar dune sands come out consistently low, even for deposits as young as $25 \mathrm{ka}$, dated by alternative methods, and the difference becomes greater with increasing age up to $350 \mathrm{ka}$. Some of his data are shown later in Fig. 7.
A similar trend is discernible in the very large data set of Berger et al. (1994), to be discussed in Section 7. This also may be attributable to fading.

\section{3. $\delta^{18} \mathrm{O}$ isotope stages and the Brunhes-Matuyama magnetic reversal}

The worldwide sea-level variations based on oxygen isotope ratios (Shackleton et al., 1990) provide geological time-markers which give independent quasi-absolute calibration for luminescence dating well beyond its present limits. In some cases the high stands of successive interglacial stages are identifiable without ambiguity in geomorphic features being dated, as are probably also the sub-features of stage 5. Figure 4, from Hütt et al. (1993), illustrates this point. Similar comparisons of TL ages and isotope curves back to and beyond stage 5 are to be found in Dutkiewicz and Prescott (1997).

The Brunhes-Matuyama geomagnetic field reversal (Spell and McDougall, 1992; Bassinot et al., 1994) provides a further definitive time-marker at $780 \mathrm{ka}$ against which luminescence dating can be tested.

A good example of this is to be found in the fossil dune system in the south-east of South

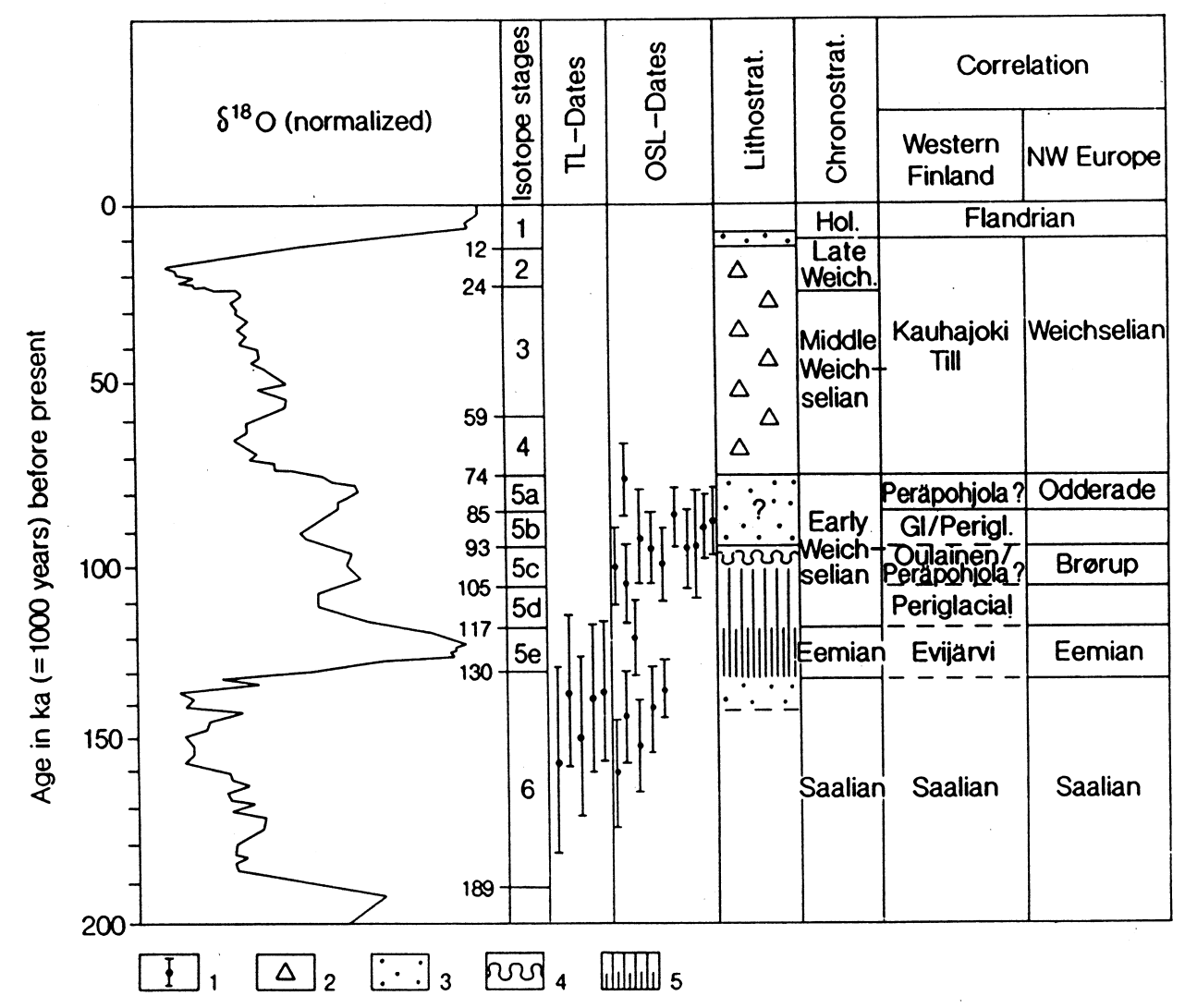

Fig. 4. TL and OSL ages from southern Ostrobothnia, illustrating the potential for comparisons between luminescence ages, $\delta^{18} \mathrm{O}$ isotope stages and standard chronostratigraphy of NW Europe. 1) Error bars are one standard deviation; 2) till; 3) sorted sediment; 4) cryoturbated sediment; 5) organic sediments and podsols (after Hütt et al., 1993). 
Australia. As recognised by Australian geologists, these dunes represent successive high stands of the sea, laid down on a tectonically slowly rising land surface, and corresponding to the interglacial stages. Spread about $10 \mathrm{~km}$ apart in distance and $120 \mathrm{ka}$ in time, their ages run from zero at the coast to beyond $800 \mathrm{ka}$ at Naracoorte where the Brunhes-Matuyama boundary is known to lie between the West and East Naracoorte Ranges. Since the members of this set of ranges have been related to sea-level curves based on $\delta^{18} \mathrm{O}$ isotope measurements, and other geological evidence, the prospects for a test of TL dating in this time range were good and have since proved to be so (Huntley et al., 1993a,b, 1994; Belperio, 1995).

The TL ages were obtained on $100 \mu \mathrm{m}$ quartz grains from inside the dunes, using total bleach on the $375^{\circ} \mathrm{C}$ peak with allowance for residual $\mathrm{TL}$ and the Australian Slide method of analysis (Prescott et al., 1993). Satisfactory agreement between TL ages and geologically fixed ages was found back to about $500 \mathrm{ka}$. Older than that, the TL data cannot always be fitted using the Australian Slide doseshift procedure. The IRSL ages tend to be underestimates. There is also some limited latitude in assigning particular fossil dunes to particular peaks in the $\delta^{18} \mathrm{O}$ record. These ages are plotted in Fig. 9 in connection with Section 9.3, where they are further discussed.

The same procedures have subsequently been used to find ages of $178 \pm 13,237 \pm 16$ and $320 \pm 22 \mathrm{ka}$ of fossil dunes $100 \mathrm{~km}$ to the south of the previous set. These were not intended as a test of TL but rather its application, together with amino acid racemisation, to the problem of defining Quaternary uplift in the region (Murray-Wallace et al., 1997).

\subsection{Ongoing themes}

The previous section has introduced examples of some of the successful applications of luminescence dating. Here we use "successful" not in the sense of having obtained a number and an error limit but in the sense of yielding an age validated by comparison with independent criteria. Where this is not the case, matters for further consideration are suggested, fading for example. In the remaining sections we present specific examples of contexts in which luminescence dating has been applied and discuss the conditions under which credible ages may be obtained, and where they may not.

\section{WIND-BLOWN DUNES AND SIMILAR ASSOCIATIONS}

Dune systems, particularly those which are rich in quartz and are located in sunlit regions, provide ideal materials for luminescence dating. They are well suited to contribute to studies of past climate changes in various environments. The work up to 1992 has been well reviewed by Wintle (1993) and this section brings that account up to date with examples from different continents and with particular reference to the less well bleached materials. We start with TL.

\subsection{Thermoluminescence}

Working in Australia, Bryant et al. (1994) have built up a large suite of TL dates for aeolian dunes and coastal foredunes along a considerable part of the New South Wales coastline in their study of the environments, including palaeoclimates, of Eastern Australia throughout the last Glacial. The TL techniques were standard for the Wollongong laboratory, i.e. using $100 \mu \mathrm{m}$ grains of quartz, a combined regenerative/additive dose method of analysis of the $375^{\circ} \mathrm{C}$ peak, but without correction for possible residual non-bleached TL. Ages in the range 14-65 ka were backed by uranium series dating. Using the same samples Nott et al. (1994) studied the reworking of dune sands and its effect on the integrity of stratigraphic sequences. It may be noted that Berger (1995) considers that the Wollongong procedures may be inadequate for ages older than $50 \mathrm{ka}$, largely because of the lack of independent validation of their methods.

In Central Australia, Nanson et al. (1995) studied the dunefield of the western Simpson Desert using standard Wollongong techniques of dating but making corrections for residual TL levels from the TL of surface samples. They claimed excellent plateaux and growth curves (though none of these are shown). Second-glow curves were used to distinguish samples of quartz from different origins (see also Price, 1994). They used the ages to develop theories of orientation of the dune systems in relation to wind direction at present and in the past. In particular they proposed that there was a bodily northward shift in the wind pattern by a degree or two of latitude during the last Glacial but during this period the dune pattern has remained stable.

We have already mentioned the comprehensive test of dating of sediments using TL and IRSL which was carried out by Huntley et al. (1993a,b, 1994) on the sequence of sand dunes in the southeast of South Australia. These dunes represent former interglacial high sea levels and have been securely related to oxygen isotope ages.

In Europe, Selsing and Mejdahl (1994) made TL measurements on feldspars from aeolian sand dunes of late Holocene age in south-west Norway and compared them with ${ }^{14} \mathrm{C}$ ages. While recognising the possibility of incomplete bleaching, they used the total bleach method of analysis. They concluded that it is possible to date well-bleached sediments as young as $1.6 \mathrm{ka}$. 


\section{2. $O S L$}

The above examples illustrate that recent TL applications have been successful in arid environments where the bleaching of the TL signal is likely to have been complete. Optical dating provides a method that is less influenced by incomplete bleaching problems and is now gaining support in more temperate environments, such as in Britain, northwest Europe, the American continent and in New Zealand.

Validation of the optical dating of sand dunes was carried out by Stokes and Gaylord (1993) for the Holocene dune sands in the Ferris Dune Field, Wyoming, where one of the most continuous aeolian sequences in the U.S.A. occurs. Seven dune samples in vertical stratigraphic succession were collected from sites which had been ${ }^{14} \mathrm{C}$ dated. GLSL of coarse grain quartz was used. Good agreement was obtained between ${ }^{14} \mathrm{C}$ and $\mathrm{OSL}$ for ages in the range 4-8 ka, reinforcing earlier findings that dune building and accumulation occurred during the Holocene. This comparison is that already shown in Fig. 1. This work is of additional interest in that GLSL was successfully applied, notwithstanding that the quartz was found to be atypical, in that the rapidly bleaching peak was almost absent and the GLSL intensity small.

Aeolian sediments from the Sefton Coast, northwest England (Pye et al., 1995) yielded ages in the range $0.16-8.3 \mathrm{ka}$ which were consistent with ${ }^{14} \mathrm{C}$ ages and with historical evidence, but more dates are needed in order to test hypotheses which relate aeolian events to changes in climate and sea level.

In Africa, Stokes et al. (1997) studied aridity changes in the north-eastern Kalahari Desert during the last Glacial cycle, obtaining evidence of at least three episodes of linear dune deposition at $\sim 20-30$, 40-50 and $100-110 \mathrm{ka}$. It was foreseen that this chronology could be extended back $\sim 500 \mathrm{ka}$ due to low environmental dose rates, $\sim 0.5 \mathrm{~Gy} \mathrm{ka}^{-1}$, similar to the situation in the south-east of South Australia (Huntley et al., 1993a).

Two of the same team (Stokes and Horrocks, 1997) carried out a reconnaissance survey of the linear dunes and loess plains of north-western Nigeria, showing that the two elements were not contemporaneous, as previously thought, but that the loess plain was older, probably dating from before the last Glacial. We suggest that this observation possibly expresses the fact that the quartz dune material is easier to remobilise than the Quaternary silty clays.

Lundqvist and Mejdahl (1995) used TL and OSL to study deglaciation in Northern Sweden. The samples were derived from sand dunes in Norrbotten. Quartz was used for GLSL, whereas feldspars were used for TL and IRSL. Usually there was good agreement between OSL and TL results in the age range $7-11 \mathrm{ka}$, but not with previous ideas of glaciation, because TL ages were generally too low and the range too great. A number of possible reasons are discussed, including the possibility that the dune formation was not strictly related to the presence of ice.

Since the luminescence dating method determines the last time a sediment has been exposed to sunlight, it can provide a useful indicator of old sand dunes which have been reworked in more recent times, as in northern Nigeria mentioned earlier (Stokes and Horrocks, 1997). Dune activity depends on sand supply, temperature, precipitation, vegetation and wind direction, such that in periods of drought there may be increased activity due to lower groundwater levels and reduced vegetation cover.

These considerations prompted the application of IRSL to the dating of dune sediments from the North Island of New Zealand (Duller, 1996a). Potassium-rich feldspars were extracted from the samples and single aliquot additive dose measurements were made. Ages ranged from 10 to $43 \mathrm{ka}$ and supported the notion that the original deposition of the dunes occurred at 40-50 ka or earlier, no dune activity occurred between 40 and $24 \mathrm{ka}$ and dune remobilisation occurred between 24 and $10 \mathrm{ka}$.

Climate changes in the arid and semi-arid regions were of interest to Juyal et al. (1997), and it was recognised that IRSL might provide a chronology for events in south-east Arabia, especially in Oman where other data are limited to a few ${ }^{14} \mathrm{C}$ dates and a single U/Th age. Samples were collected in Oman and in The Emirates and feldspar grains extracted. Infrared readout exposures were limited to $12 \mathrm{~s}$ so that TL measurements could be subsequently carried out on the same samples. Ages ranging from 10 to $300 \mathrm{ka}$ have provided a framework for the times of deposition of Quaternary sediments in the region and it is anticipated that further sampling could add to an eventual understanding of the past climates of the region. This is a good example of the survey use of luminescence.

Various aspects of dating young dunes were considered by Ollerhead et al. (1994). The material was derived from the Holocene Buctouche Spit in New Brunswick and contained both K-feldspars and quartz from which both purified coarse grains and polymineral fine grains were extracted. Ages obtained for K-feldspar stimulated by IR were in the range 5 to $765 \mathrm{a}$. TL ages obtained for the quartz, although less precise than the IRSL ages, confirm the recent formation of the dunes. The luminescence dates, together with geomorphological evidence, suggest that the Buctouche Spit formed during the past $2 \mathrm{ka}$ and the surviving dunes at the distal end during the past 800 a.

Wolfe et al. (1995) applied IRSL to dune activity in south-western Saskatchewan; ages as young as $70 \mathrm{a}$ and as old as $2.6 \mathrm{ka}$ were obtained. 
The Mojave Desert in California contains widespread relict aeolian deposits and landforms which provide information on climate change back into the Pleistocene. These sands have been dated using various luminescence methods. Working with sand ramps from the Dale Lake region and sand dunes in the Cronese Mountains, Rendell et al. (1994) identified some of the inherent problems, particularly the need to select samples carefully to avoid mixtures of aeolian and colluvial material. Despite discrepancies between the dates obtained by TL and IRSL, they identified two periods of sand deposition: $>35$ to $25 \mathrm{ka}$ and 15 to $10 \mathrm{ka}$.

Following the work of Edwards (1993), Clarke (1994) used the IRSL method for potassium feldspars for six sites on the north-eastern edge of the Kelso Dunes in the Mojave Desert. Potassium feldspars were dated using the single aliquot procedure of Duller (1991). Ages obtained ranged from 4 to $17 \mathrm{ka}$.

IRSL methods were also tested by Wintle et al. (1994) on feldspar extracts from the Kelso dunes. A surface sample had an age of $40 \mathrm{a}$ and there was evidence of reworking in areas with ages of 845$105 \mathrm{a}$. At the eastern end of the dune field, sand samples had an age of $4 \mathrm{ka}$ and at the western end $1.5 \mathrm{ka}$, indicating two different phases of aeolian activity.

Clarke et al. (1995) studied sand deposition at the Cronese Basin, Kelso Dunes and Silver Lake in an attempt to determine whether sand movement can be related to climate change including episodic pluvial activity. IRSL ages obtained were combined with ages obtained by previous work and related to documented pluvial phases in the Late Pleistocene and Holocene. Sand deposition also occurred during periods of aridity.

\section{LOESS}

Loess is a fine, wind-transported material which, because of its grain size, usually spends considerable time in transport. These are particularly favourable conditions for resetting the luminescence clock by exposure to daylight. Typically, $80-90 \%$ of loess grains are less than $50 \mu \mathrm{m}$ and $10-15 \%$ are less than $10 \mu \mathrm{m}$ (Wintle, 1990; $\mathrm{Hu}$ and $\mathrm{Lu}, 1985$ ). This range of sizes favours the use of fine grain procedures and most work on loess has been carried out with undifferentiated fine grains of 4-11 $\mu \mathrm{m}$ after removal of carbonate.

The issues set out by Wintle (1990) still apply. She stated that since fine grains are usually undifferentiated mineral mixtures and, as such, contain feldspars, they are subject to the usual problems, i.e. possible fading, choice of filter for the recording wavelength, sensitisation on bleaching and choice of preheat and analysis procedures. These problems are common to all fine-grained sediments. Quartz, for which difficulties appear more tractable, has been extracted from loess for dating purposes, but may be limited to younger sediments if it saturates early.

Wintle's 1990 review dealt only with thermoluminescence dating. The subsequent development of optical dating has resulted in its gradual introduction to loess studies. This is particularly appropriate since optical stimulation excites those traps that have been reset by light during the transport mechanism. Nevertheless, up to the end of 1996 most of the age determinations of loess have still been by TL. However this will change as facilities for optical dating become more widely available. Some examples appear in other sections of the present review.

The loess deposits in China, central Asia, Europe and the USA provide extensive records of past climate, allowing the reconstruction of long-term climatic fluctuations (Liu and Yuan, 1987). Kukla (1987) gives a correlation of Chinese, European and American loess sequences with deep-sea sediments. Liu (1985) once claimed that the longest, best characterised loess sequences in China provide a more detailed record, over $2.4 \mathrm{Ma}$, than do the marine core $\delta^{18} \mathrm{O}$ records. While this may well have been true in 1985, it is arguable now.

Zhou et al. (1995) present TL ages for the Orkutsay loess section in the Tashkent region of central Asia, specifically relating it to earlier work from the same region. This appears to be the first direct comparison of ages obtained by contemporary protocols with early work from the then USSR, and with other regions. They obtained TL age estimates ranging up to $134 \mathrm{ka}$ but they consider that these are considerably underestimated. They conclude that fading is not yet sufficiently understood and that as a consequence,

.....the present study allows us to draw the following conclusion. It is highly unlikely that any published data for Central Asia loess below the uppermost-placed palaeosol (PC1) [their notation, 45 ka] have any chronological significance.

In this statement, Zhou et al. include their own work. This paper is worth consulting for the range of little known references from the former USSR.

For the US, Berger and Busacca (1995) have dated late Pleistocene deep loess profiles from eastern Washington State, using polymineral 4-11 $\mu \mathrm{m}$ grains. Ages obtained range from 17 to $83.2 \mathrm{ka}$. This set of measurements is of particular interest in that tephra beds from eruptions of Mt. St Helens are interspersed with the loess. TL ages for 4$11 \mu \mathrm{m}$ glass from the tephra were also found. Their profiles are shown in Fig. 5. The significance of these ages for the eruption history of Mt. St Helens is discussed in Section 7.1.

Richardson et al. (1997) have carried out both TL and IRSL determinations of loess deposits from 

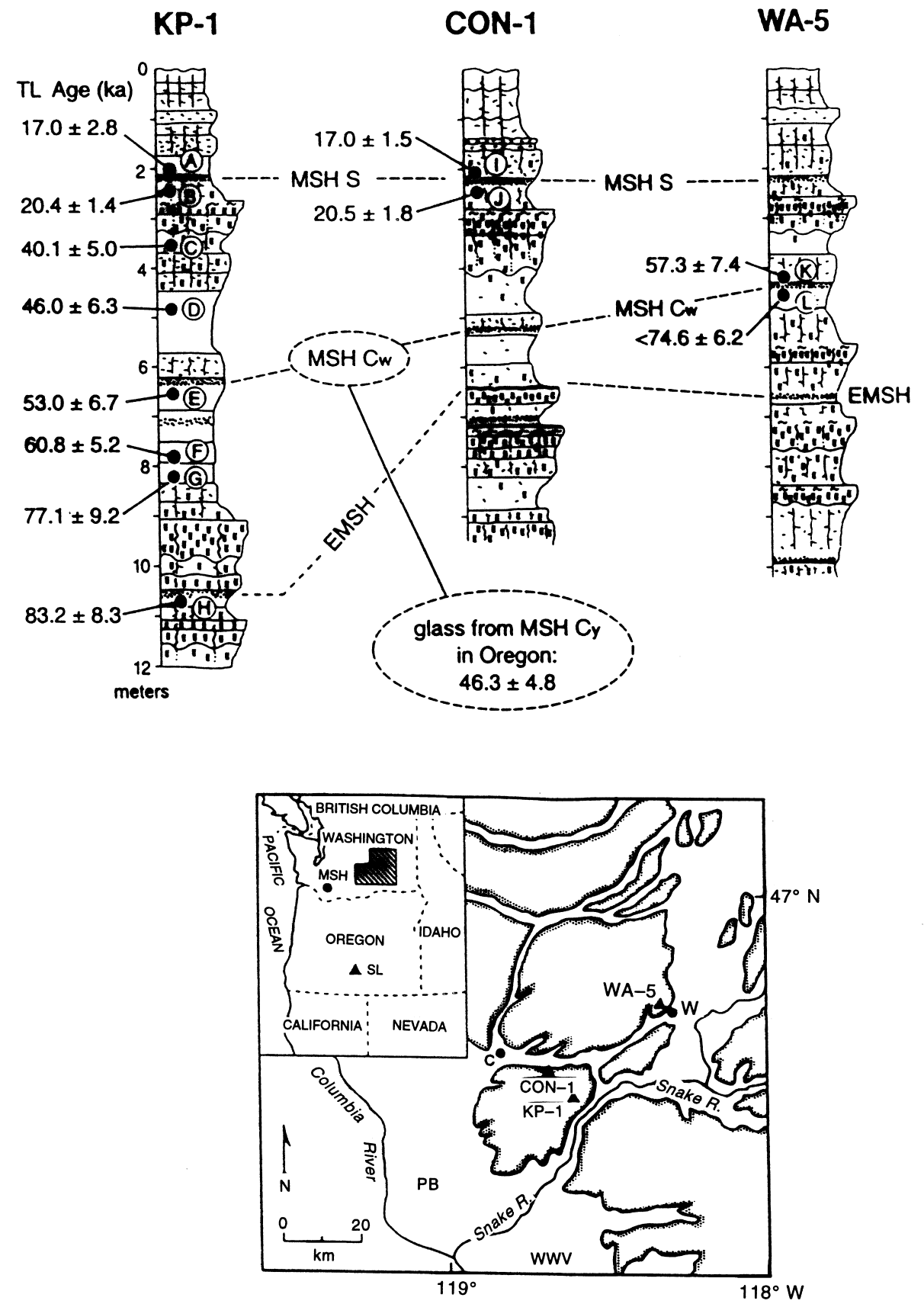

Fig. 5. Loess profiles from sample sites in south-east Washington State, USA. These are shown on the map, which also indicates the general location of the main sources of supply of the loess $(P B$ and $W W V$ ). Polymineral fine grain TL ages for deposition of the loess profiles are indicated on the figure in ka. The profile has an additional interest in that tephras from eruptions of Mt. St Helens (indicated by MSH) are interbedded with the loess and have been dated by loess above and below the tephra. The implications for the eruptive history of Mt. St Helens are discussed in Section 7.1 (adapted from Berger and Busacca, 1995). The figure is also appropriate for the work of Richardson et al. (1997).

the same region of Washington State as Berger and Busacca, including revisiting some of the same sites. Twenty-seven age pairs were determined for seven sites, covering a nominal age range of $18-160 \mathrm{ka}$. Generally speaking, the TL ages of Richardson et $a l$. are consistently younger than the corresponding ages of Berger and Busacca; no explanation is offered for this difference.

An interesting insight into methodology is offered by their comparison of the TL and IRSL age pairs. The $D_{\mathrm{e}}$ for IRSL is found to be consistently smaller than the $D_{\mathrm{e}}$ for TL, and increasingly so with 
increasing $D_{\mathrm{e}}$. A similar difference was obtained by Musson et al. (1994) for a Lujiapo site in China. Neither reference offers a resolution of the discrepancy but states that the TL ages correspond better than IRSL with independent evidence. Resolution of this difference would appear to call for a study of the physics of the materials concerned to determine if it is a local or global effect.

Zöller et al. (1994) present a substantial reconciliation of loess stratigraphies from Austria, Hungary and the Czech Republic. With the aid of 41 new TL age determinations supported by amino acid racemisation, an inter-regional correlation of loess-palaeosol sequences is put forward. Polymineral fine grains were employed with a "strong thermal wash" of $5 \mathrm{~min}$ at $270^{\circ} \mathrm{C}$ before regular TL readout with a Schott 5-58 filter. Ages were found for three samples using coarse grain quartz and feldspar. These authors consider that the fine grain ages older than 50-100 ka are underestimates, but that a number of ambiguities in the stratigraphy is resolved and a new stratigraphic frame is emerging, as shown in Table 1.

Dating of loess in New Zealand and Alaska by Berger et al. (1994) is discussed in Section 9. Although Australia has significant areas of windblown dust mantle, they are shallow and not usually classified as loess. No luminescence dating seems to have been carried out on the extensive loess deposits in South America.

\section{WATER-LAID DEPOSITS}

\subsection{Setting to zero}

The problem of zeroing the natural TL of sediments which are laid down by transport in water was recognised early in the development of dating methods for sediments (Wintle and Huntley, 1982) and it was predicted that the likelihood of dating such deposits was slim. The case has been discussed in the comprehensive review of Berger (1995): the turbidity of a suspension of silty particles, the selective screening of light of various wavelengths/pho- ton energies, the presence of light-absorbing organic matter and the different responses of different minerals, quartz and feldspars, combine to complicate the issue. However the advent of OSL and the possibility of selecting the optimum wavelengths for the stimulating light is helping to refine the techniques.

\subsection{Fluvial sediments}

The zeroing of the TL of the suspended silt in the Fraser River was considered by Berger et al. (1990) in terms of the underwater ambient light spectra, the TL responses of suspended grains and recently deposited sediments, and the TL dating of mud cores of known and unknown age, recovered from the Fraser River. It was found that most of the light-sensitive TL in fine grains was removed prior to deposition. Other studies by Berger and his coworkers from 1990 onwards are detailed in his review (Berger, 1995).

Mejdahl and Funder (1994) tested a large number of sediments from different sources in east Greenland using TL and OSL of sand-sized feldspars. They found that even though zeroing of the signal was incomplete in many samples it was possible to date samples by comparing the results of dating K-feldspars by TL (partial bleach/regeneration) and by IRSL (additive dose). Shallow marine and fluvial sediment ages fell within $15 \%$ of the ages expected from biostratigraphy and ${ }^{14} \mathrm{C}$ dating. Ice-proximal glaciolacustrine and glaciofluvial sediments were unsuitable because the sand grains had been differently bleached and some even retained an intact signal from earlier events.

We note here an unusual intercomparison to be found in Mejdahl and Funder (1994) where mollusc fauna and plant and insect assemblages are used to identify the last interglacial $\delta^{18} \mathrm{O}$ isotope stage 5e for comparison with TL and OSL.

Murton et al. (1997) studied aeolian and fluvial activity at the Pleistocene Mackenzie Delta in the Canadian Arctic. The samples were derived from aeolian sands deposited on top of ice surfaces

Table 1. Proposed stratigraphic position of paleosols in Austrian, Hungarian and Czech loesses

\begin{tabular}{ll}
\hline Stratigraphical age & Soil and locality \\
\hline Late Würmian & $\mathrm{H}_{1}$ and $\mathrm{H}_{2}$ weak humic soils (Sülysáp/Hungary) \\
Middle Würmian interstadial(s) & Stillfried B (Stillfried/Austria) PK 1 (Dolní Věstonice/CR) \\
& $\mathrm{MF}_{1}$ (Mende and Basahárc/Hungary), Bohunice soil? (CR) \\
& Stillfried A upper part, Paudorf Soil (PA II, GÖ 1, upper part) \\
& "Wurmröhrenlöß" Wels/Austria; MF upper part (Mende and Basahárc/ \\
Early Würmian interstadials & Hungary) PK II and PK III upper part (Dolní Věstonice/CR) \\
& Stillfried A (lower part) Paudorf Soil (PA II, GÖ I, lower part) 1st fBt (para- \\
& brown earth, Wels), MF ${ }_{2}$ lower part (Basahárc, Páks, Mende/Hungary) PK III \\
Last interglacial & lower part (Dolní Věstonice/CR) \\
Penultimate interglacial & Lower Paudorf Soil (PA 1) BD pedocomplex (Basahárc, Mende, Páks/Hungary) \\
Older interglacials & Göttweig Soil (GÖ II, type locality at Göttweig/Austria) BA paleosol, Hungary \\
& MB pedocomplex, Hungary \\
\hline
\end{tabular}

(After Zöller et al., 1994). 
which had been fluvially eroded by meltwater activity. ${ }^{14} \mathrm{C}$ ages were available from roots occurring in the ancient thaw layers. Coarse grain feldspars and fine grain polyminerals were extracted from four sand samples and analysed by IRSL using a blue transmitting filter to observe the emission. A set of seven ages showed good agreement between coarse and fine grains. The age of $14 \mathrm{ka}$ suggests that ice last covered the area somewhat later than previously understood.

Nanson et al. (1992) present a synthesis of their work on chronology for both aeolian and fluvial deposits across much of central and eastern Australia to reveal an alternating pattern of episodes associated with the Quaternary Interglacials and Glacials. Three contrasting environments are represented: hot dry deserts, the riverine plain and coastal river valleys (75 TL and $18 \mathrm{U} / \mathrm{Th}$ ages are shown in histogram form).

A detailed account of the work on the Riverine Plain is given in Page et al. (1996). Here they focused on the palaeochannels in the MurrayGoulburn sector which controlled the patterns of soil and sediment variation. Each palaeochannel was sampled at intervals along its length. TL dating was used and the question of incomplete bleaching of these fluvial samples was checked by comparing the age found when the quartz rapidly-bleaching peak at $325^{\circ} \mathrm{C}$ was used with the age from the slowly-bleaching peak at $375^{\circ} \mathrm{C}$. Good agreement provided evidence that bleaching had been effective. The results show consistency within the set of ages for each individual channel and the ages show that individual channels developed during the last Glacial between 105 and $20 \mathrm{ka}$, concentrated in four episodes: at 105-80, at 55-35, at 35-25 and at 20-13 ka. This elegant work is shown in Fig. 6(a) to $(\mathrm{d})$.

\subsection{Lacustrine deposits}

A few references to the dating of lacustrine sediments are included in papers discussed elsewhere in the present paper, but there have been surprisingly few studies devoted to the dating of lake cores specifically. This situation may have arisen from an earlier perception that the dating of sediments lying deep within a lake would be fraught with difficulties in determining the degree of bleaching of the TL signal and in determining what the dose rate would be in this type of environment.

This perception has not been much modified even by the efforts of the most persistent worker in the field (Berger et al., 1987; Berger, 1988; Berger and Easterbrook, 1993; Berger and Anderson, 1994). The earliest of these papers shows that the types of situations most amenable to dating are likely to be found in larger lakes with broad low-gradient floors and in places where clay rather than silty layers pre- dominate. Ages well beyond the limit of ${ }^{14} \mathrm{C}$ dating were shown to be measurable. Berger and Anderson (1994) concentrate on Squirrel Lake in arctic Alaska. The core went down to $14 \mathrm{~m}$ with ${ }^{14} \mathrm{C}$ ages down to $3 \mathrm{~m}$. As $\mathrm{TL}$ and ${ }^{14} \mathrm{C}$ ages were in good agreement for these upper layers it was inferred that the technique could be taken as reliable to the lowest level with a TL age of $125 \pm 31 \mathrm{ka}$.

In the Antarctic, Krause et al. (1997) collected sediment cores from lakes in an ice-free area, using plagioclases for IRSL dating. The emission spectra were analysed to identify the most readily bleachable peak as observed at $560 \mathrm{~nm} / 2.2 \mathrm{eV}$. This paper is a rarity in that spectrometry was used in advance to devise a measurement protocol. We commend this practice. Ages of 7 to $53 \mathrm{ka}$ were found from the top to the bottom of the core.

TL dating in an arid lacustrine environment was carried out by Dutkiewicz and Prescott (1997) on the strandlines of playas in the Lake Malata-Lake Greenly complex on Eyre Peninsula, South Australia. The gypsum/carbonate lunettes provided adequate quartz grains and as the grains had been deflated from the basin during lunette formation in direct sunlight, the TL was thoroughly bleached at the time of deposition. Stabilisation of the lunette by calcrete capping occurred early due to rapid absorption of water during wet periods and they were unlikely to have been reworked subsequently. Total bleach methods were mainly used and complete sets of glow curves, growth curves and $D_{\mathrm{e}}$ plateaux are presented. The oldest carbonate lunette had an age of $115 \mathrm{ka}$ and there were several further stages of lunette formation up to about $1 \mathrm{ka}$. A foredune, Lake Malata Ridge, was shown to have an age of $320 \mathrm{ka}$, representing a unique wet phase in the evolution of the lake complex. This suite of luminescence ages is compared with the $\delta^{18} \mathrm{O}$ sealevel record and, within the uncertainties of $\mathrm{TL}$, allows an interpretation of climate change.

We note one curiosity from this work: it was carried out in an environment where the lunettes/dunes have a high gypsum content. Dose rates normally lay between 0.8 and $2 \mathrm{~Gy} \mathrm{ka}^{-1}$. For one lake-proximal dune, consisting of almost pure gypsum, the dose rate as measured with an in situ scintillometer was not significantly different from zero. It could have been any age!

\subsection{Colluvial sediments}

Although the formation of colluvial (slope deposit) sediments is not exclusively due to the action of water, we include it here because of its affinity to this section.

The sediment transport processes in the deposition of colluvial deposits are such that light exposure is likely to be far less than for aeolian processes, with grains and aggregates of grains of 

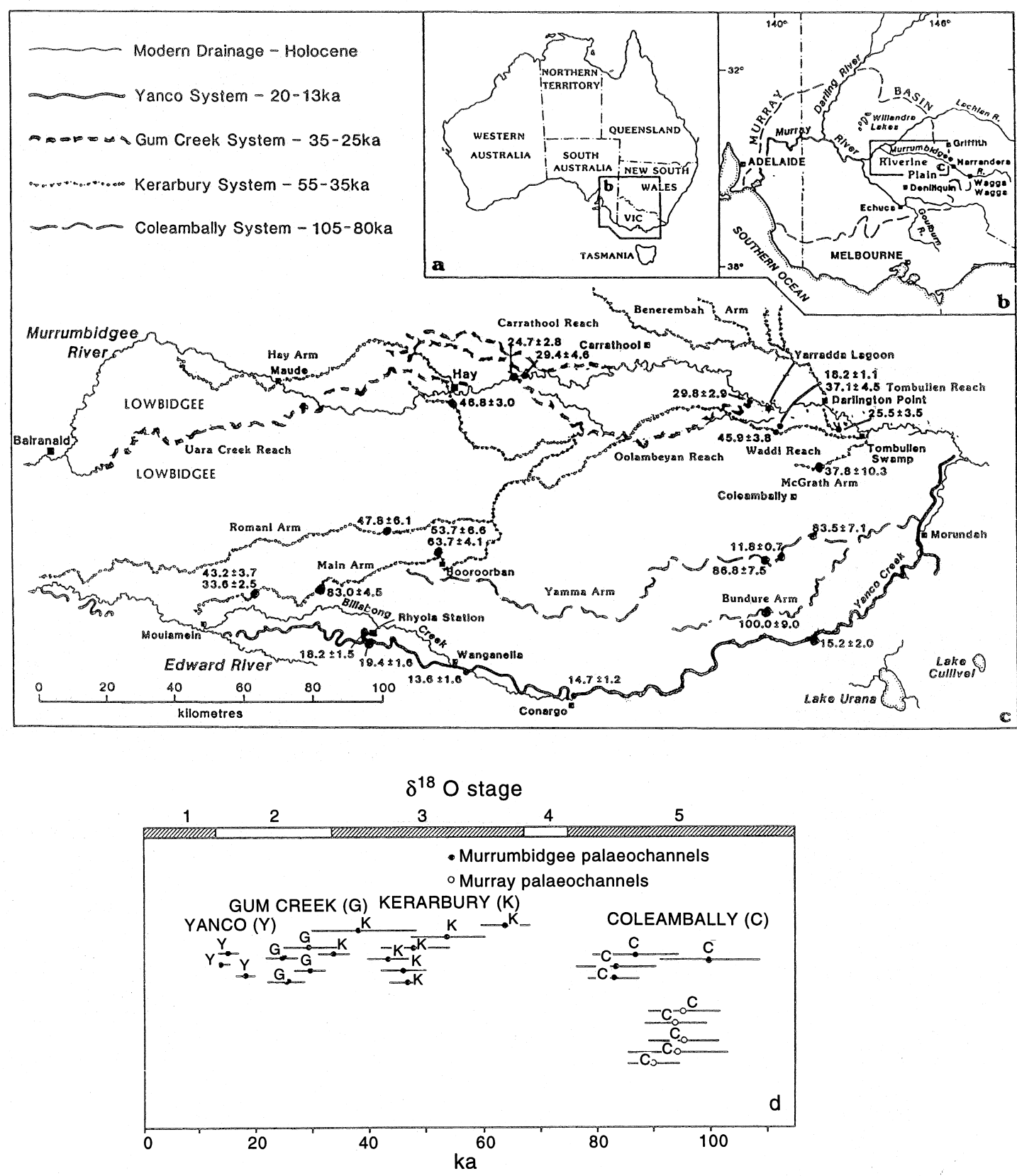

Fig. 6. The Murrumbidgee, Australia, palaeochannel system, illustrating an aspect of its fluvial history. Quartz $100 \mu \mathrm{m}$ TL ages for four palaeochannel systems are shown on the map and these are collected together in (d), which also shows oxygen isotope stages. Some original detail is omitted for clarity (after Page et al., 1996).

all sizes possibly being transported, deposited and covered during a single event, for example, heavy rainfall. Some grains may be well bleached by sunlight, whereas others may be poorly bleached.

Wintle et al. (1993) tested various luminescence methods for dating colluvium exposed in the walls of a donga in northern Natal. Fine grain samples were measured by TL, by multi-disc IRSL and by single-disc IRSL. Total bleach and regeneration methods of analysis were applied. There was agree- ment among the ages obtained using the IRSL methods and some of the radiocarbon dates but the TL dates were much older than the rest, some by a factor of two. Suggested explanations lie in the insufficient bleaching of colluvial fine grains which experienced only one cycle of erosion and deposition, and the possible instability of the IRSL signal with time. The same techniques were further explored by Wintle et al. (1995) but using $100 \mu \mathrm{m}$ feldspar grains. In this case, well-bleached samples 
showed good agreement between TL and IRSL ages and less variation between single aliquots of the same sample than between aliquots of the poorly bleached samples. These two papers illustrate the importance of testing methods thoroughly for each new type of material encountered.

Lang (1994) reported IRSL ages of Holocene colluvial, lacustrine and alluvial sediments and loess covering a habitation site in central Europe, illustrating that uncertainties still exist because of doubt about zeroing, even of the IRSL signal, and the best conditions for carrying out pre-heats.

Lang and Wagner (1997) studied a sequence of loess and colluvium ranging from the Pleistocene to the 17 th century, using fine grains, IRSL, multiple aliquot additive dose and a subtraction technique of Aitken and Xie (1992). A good plateau for the equivalent dose plotted against infrared stimulation time was obtained. The resulting ages were in excellent stratigraphic order from 0.5 to $16 \mathrm{ka}$.

\subsection{Dose rates and disequilibrium - a potential pro- blem in wet sites}

In dose rate determinations, the presence of disequilibrium in the uranium and thorium decay chains is a relevant factor. It is particularly important in wet environments. It may also be wise to anticipate it for the ice-proximal environments discussed later in Section 9.

In Australia, Olley et al. (1996) found that disequilibrium is common in fluvial and lacustrine environments, particularly in the $\mathrm{U}$ decay chain, but not in the Th chain. However the associated uncertainty in the dose rate was only a few $\%$, which is similar to other sources of uncertainty.

Krbetschek et al. (1994) analysed disequilibrium at several European sites using high-resolution gamma and alpha spectrometry. Among some 200 diverse samples, disequilibrium was connected only with limnic and fluvial sediments. For example, in a sequence of limnic sediments on top of a fluvial gravel on the river Rhine, disequilibrium was not detected in the upper horizons; it was found only in the basic clay layer and was assessed in terms of the fate of individual isotopes.

Further examples of significant disequilibrium are described in Wintle and Huntley (1980), Prescott and Hutton (1995) and Huntley and Clague (1996). Readhead (1987) and Olley et al. (1996) give dose rate conversion data to be applied when disequilibrium is present.

\subsection{Ocean sediments}

There appears to have been no work done on this topic since the pioneering papers of Wintle and Huntley (1979, 1980). The time may well be here for a new attack in this area.

\section{ICY ENVIRONMENTS}

There are several accounts of attempts to understand the bleaching problems of glacial and periglacial sediments (see, for example, Wintle and Catt, 1985; Gemmell, 1988a; Duller, 1994b; Berger, 1995; Duller et al., 1995). In summary, the problem is that material carried within or beneath glacier ice may not have been fully bleached at deposition. There might be some zeroing of TL by crushing and grinding during transport, but there would be a minimal effect from light. Sediment from the surface might travel downwards in the ice to form part of the basal load or it might move upwards within the ice to melt out on the surface. Because of the enduring nature of the glacier ice and its slow movement these processes may incorporate grains of varying age in the final load.

Other work on assessing the reliability of TL dating of Arctic glacial and near-shore marine sediments was carried out by Forman, working at the Polar Institute (Forman and Ennis, 1992). Reduction of the TL signal after exposure to light of various wavelengths was compared. It was concluded that in the polymineral fraction of glacial and near-shore marine sediments the residual TL could not be determined accurately, leading to overestimates of the ages of such samples by both the total and partial bleach techniques. Coarse grains were even worse as they had received even less light during transport. The conditions vary in different areas depending on the mode of transport.

Duller et al. (1995) assumed that their ice-proximal, glaciofluvial samples in Scotland had received incomplete bleaching which might have been either of two types: first, that all the grains in the sample had received the same amount of light but that this was insufficient to bleach them or second, that the sample contained a mixed set of grains which had been exposed to daylight for varying periods of time. Detailed discussion of the possibility of distinguishing between the types was given. When the ages were compared with available ${ }^{14} \mathrm{C}$ ages there was very little correspondence between them and the authors conclude that luminescence dating of periglacial slope deposits and fluvial deposits within a few $\mathrm{km}$ of the front of the ice sheet is unlikely to be successful.

Hütt, who first demonstrated IRSL signals from feldspars, has tested the technique on a number of glaciofluvial sites in eastern Europe (Hütt and Jungner, 1992; Hütt et al., 1993; Gaigalas and Hütt, 1996). At a site near Leningrad, samples which were undatable by TL because of poor plateaux produced only one realistic IRSL age of $16 \mathrm{ka}$ from a slowly defrosted sample. Others, from rapidly defrosted sites, gave unrealistically high ages. In western Finland buried fossil soils occur in sandy sediments in association with glaciofluvial deposits and were sampled for TL and IRSL analysis. IRSL ages were grouped at $120-163 \mathrm{ka}$ and $76-106 \mathrm{ka}$ 
but the TL ages were all older at $135-155 \mathrm{ka}$ and were assumed to represent upper limit estimates. The ages confirmed geological interpretation that fossil soils were formed during the last interglacial. At two sites in Lithuania, IRSL ages provided an apparently better glacial and interglacial chronology up to $114 \mathrm{ka}$.

Instrumented field experiments have been carried out by Gemmell in order to assess the effectiveness of zeroing TL in sediments during transport and under extreme conditions. The earliest of these (Gemmell, 1988a,b) were on the Austerdalsbreen glacier in Norway, where a number of transportational facies were chosen from which to drill for sediment samples. Some samples showed evidence of zeroing, others not. The TL was also observed as a function of the distance from the glacier. Further experiments (Gemmell, 1994a,b) examined residual TL levels at hourly intervals from a meltwater stream in Iceland and noted fluctuations due to ambient light levels and other factors. Most recently he has instrumented the stream (Gemmell, 1997) and examined the resetting as a function of time of day and the state of the weather and distance of transportation. He confirms that suspended sediment is a major factor in impeding bleaching.

On the whole, Gemmells's experiments, taken with the other examples given, do not encourage one to be hopeful about using luminescence dating in icy environments.

\section{TEPHRA AND OTHER HEATED MATERIALS}

Various products of volcanic activity can be dated by TL because they have been heated. The lava itself has certainly been heated to a high temperature but it may not be suitable for dating because of a lack of quartz in its composition. The volcanic ash, including glass fragments, may be blown into the air and deposited as tephra. Tephra is, of course, a sediment in its own right. It may or may not have been reset by the heat of the eruption although, from the way it is usually formed, heat resetting seems unlikely. Provided that it was ejected in daylight and spent long enough in the air before deposition it may have been reset by exposure to sunlight. The early efforts to date these materials have been reviewed by Berger (1995).

\subsection{Tephra}

Berger's work on tephra beds (Berger, 1991, 1992), in which TL ages were compared with independent ages, showed that purified glass-rich samples can be reliably dated over the age range $0.5-450 \mathrm{ka}$

Not all attempts to date volcanic glass have been successful. For example, at Mount Gambier in
South Australia the volcanic glass extracted from tephra was unsuitable for lack of a stable TL signal (Robertson et al., 1996).

Kanemaki et al. (1991) observed that the $330^{\circ} \mathrm{C}$ TL of glass fractions from tephra had a red emission at $620 \mathrm{~nm} / 2.0 \mathrm{eV}$ and attributed this to quartz and plagioclase microcrystals within the glass sherds. They were able to mechanically separate the quartz and plagioclase from the glass and used a time-resolved spectrometry system to compare the output of the various fractions. The red TL of their samples was so strong that they concluded that this signal could be used to date tephra even when it is poor in quartz.

Examples of tephra which has been indirectly dated from bracketing loess deposits come from Washington State and Oregon, USA (Berger and Busacca, 1995; Richardson et al., 1997) and from central Alaska (Berger et al., 1996). In the first example, ages for loess and related tephra layers (Fig. 5) have direct implications for the history of eruptions of Mt. St Helens, suggesting a much longer history for volcanic activity than the previously accepted age of less than $50 \mathrm{ka}$. The present mountain probably dates back to at least $80 \mathrm{ka}$ and possibly $120 \mathrm{ka}$. In the second example, direct dating of tephra layers was unsatisfactory but bracketing loess layers gave the deposition age as $190 \pm 20 \mathrm{ka}$.

\subsection{Lava flows}

The sediment layers lying beneath lava flows may have been heated adequately for the age of the flow to be found. The ages of Australia's two most recent volcanoes, Mt. Gambier and Mt. Schank in South Australia, were found to be Holocene at $4.2 \pm 0.5$ and $4.9 \pm 0.5 \mathrm{ka}$ by dating quartz underlying the main lava flow (Smith and Prescott, 1987; Robertson et al., 1996). It is worth noting that the tephra associated with these eruptions was not datable due to the lack of a stable TL signal.

The use of the red TL of quartz for such sediments was promoted by Pilleyre et al. (1992) and tested on a number of samples from volcanoes in the Massif Central of France. Samples with expected ages in the range 14-150 ka gave results which fit the geological evidence. Two older samples ( 2 and $14 \mathrm{Ma}$ ) were included for evaluation purposes but, not very surprisingly in view of their age, "hope... was not fulfilled for these samples". The authors were optimistic that a better understanding of the properties of the red luminescence might extend its use.

The extent of zeroing of the TL of the sediment under a lava flow must be considered when sampling. For example, how deep under the lava has the temperature reached high enough to reset the TL (say $400^{\circ} \mathrm{C}$ )? To answer this question 
Forman et al. (1994) carried out calculations using various values for the temperature and thickness of the lava and the temperature of the sediment layer. The calculations indicate that sampling at a depth of $20-40 \mathrm{~cm}$ would reach sediment which had been heated to $400^{\circ} \mathrm{C}$ and had its TL zeroed. The results of Robertson et al. (1996) show that at $10 \mathrm{~cm}$ below the lava flow the TL was completely reset, whereas at $30 \mathrm{~cm}$ the TL was not fully zeroed and the temperature had not reached $400^{\circ} \mathrm{C}$. At $1.5 \mathrm{~m}$ there was no evidence of zeroing.

Forman et al. (1994) obtained ages in the range 2-100 ka for sediments under lava flows on the Snake River Plain, Idaho, in agreement with ${ }^{14} \mathrm{C}$ and $\mathrm{K} / \mathrm{Ar}$ ages. A much older sample ( $600 \mathrm{ka}$ by $\mathrm{K} /$ Ar dating) was beyond the range of TL because of saturation, anomalous fading and very high dose rates (from 4 to $7 \mathrm{~Gy} \mathrm{ka}^{-1}$ ). Their results support the view that TL chronology is useful for dating volcanic events during the Quaternary, provided that baked sediments can be accessed.

It might be noted here that an interesting approach to the dating of lava itself was reported by Guérin and Valladas as far back as 1980 (Guérin and Valladas, 1980). They used the plagioclase feldspar fraction and overcame the anomalous fading associated with this material by using the high-temperature peak above $500^{\circ} \mathrm{C}$ for the analysis. They obtained well-validated results for a range of different plagioclases with ages from 9 to $200 \mathrm{ka}$. This method has not been followed up, as far as we know, possibly because of lack of facilities to deal with high temperatures or complications in calculating alpha dose rates within feldspar grains.

Zink and Visocekas (1997) have shown that the near infrared TL emission (590-750 nm/2.1$1.65 \mathrm{eV}$ ) of sanidine feldspars seems to be stable with time and has the potential for dating of materials otherwise subject to anomalous fading when observed in the "blue" $(3.1 \mathrm{eV})$. The authors suggest that the method may be applicable to the dating of lava.

\subsection{An archaeological aside}

An example of dating volcanic sediment for its archaeological significance also appeals to us on other grounds: Liritzis et al. (1996) investigated a little-known volcanic site on the island of Yiali in the Aegean Sea, not far from well-known Santorini, where the volcanic eruption is thought to have severely affected the Minoan civilization. Four rather scattered quartz TL ages were obtained with a mean value of $3.25 \pm 0.39 \mathrm{ka}$ (our recalculation). This is consistent with the second millennium BC ${ }^{14} \mathrm{C}$ age assigned to the eruption of Santorini (Bruins and van der Plicht, 1996). It may be that discussion of the decline of the Minoan civilization will need to take account of events on Yiali. As far as Santorini itself is concerned, the age of the erup- tion is very securely dated by high quality ${ }^{14} \mathrm{C}$ and tree ring chronology and would provide an excellent opportunity for a calibration of luminescence dating for tephra in this time range.

\section{SOME IMAGINATIVE APPLICATIONS}

Some less common applications of sediment dating are listed here to give some indication that its potential usefulness is limited only by the imagination. In general we have included only one or two recent examples of each.

\subsection{Sediments and their associations}

A number of geological features, which are not themselves sediments, have been dated by using sediment dating techniques on related materials.

8.1.1. Lava. We have already discussed the possibility of finding the age of a lava flow by finding the age of resetting by heat of underlying sediments. It is mentioned here because there have been few such ages determined and so it still counts as a rarity.

8.1.2. Peat beds, etc. Lian et al. (1995) have evaluated the prospects for dating organic-rich and peat beds in British Columbia and Washington State by extracting sediments from within the deposit. IRSL and TL on fine grains were used and ages ranging from zero to $100 \mathrm{ka}$ were found to be in agreement with parallel evidence. An age of $660 \mathrm{ka}$ for a sample of putative age $\sim 1 \mathrm{Ma}$ is believed to be too young. IRSL is recommended for future work because of its simplicity and greater precision. Such deposits present particular difficulties in assessing dose rates because of changing conditions of water content and the ever present possibility of radioactive disequilibrium. These authors list previous attempts to date such materials.

8.1.3. Tsunami. From time to time tsunami leave deposits in their wake. These take the form of sheets of sand or gravel carried forward by the tsunami and dumped up shore. On the assumption that the materials were well exposed to light before transport for long enough to reset the dating "clock" and were then covered by tidal or other deposits, they can be dated.

Bryant et al. (1992) found evidence for tsunami sedimentation on the south-east coast of Australia, with TL ages of several events since $3 \mathrm{ka}$ BP. Wood (1994) has also described boulder deposits consistent with storm surges or tsunami in Tunisia and has found coarse grain quartz GLSL ages for the deposit and its surroundings. The ages, described as "preliminary", suggest an episode from oxygen isotope stage $5 \mathrm{e}$.

Huntley and Clague (1996) have found IRSL ages for recent tsunami sands in the Pacific Northwest, Canada and the US. Three of these, 
with a mean age of $306 \pm 41$ a are considered to date a common event. A fourth, $1.285 \pm 0.095 \mathrm{ka}$, agrees with other independent evidence.

Dawson et al. (1995) find a TL age of $260 \pm 60$ a for deposits tentatively interpreted on other grounds as having been laid down by a tsumani resulting from the Lisbon earthquake of 1755. The TL measurement thus supports the field interpretation.

8.1.4. Pedogenic deposits. Once sediments are in place, reworking by wind or water is possible, and it is the most recent movement that would be dated. However, weathering also gives rise to formation of soils, silcretes and calcretes. Examples of palaeosols embedded in the Chinese loess sections are well known and have been comprehensively linked to climate change (Liu, 1987).

In finding the age of a palaeosol, it is often difficult to know just what is being dated. It may very well be the time of original deposition of the sediment which is dated; it is also possible that bioturbation has reworked the soil (Huntley et al., 1983; Paton et al., 1995; Williams, 1968). However, a reasonable age can be found by age-bracketing the palaeosol above and below in the profile (Musson et al., 1994). Zöller and Wagner (1989) have discussed the application of TL to dating palaeosols; and Berger's (1995) review describes a number of North American ages from buried soil horizons with comparisons with ${ }^{14} \mathrm{C}$. In passing, we note that bioturbation is mentioned from time to time in connection with sediment dating but no one seems to have evaluated its effect on the age found for the sediment.

Pedogenic carbonate presents a challenge to luminescence dating which has barely been taken up. In principle, the age of formation of the carbonate could be found directly because the zero of time presumably coincides with the crystallisation of the carbonate. May and Machette (1984) explored the possibility of using TL to date soil carbonate but they did not carry it further and the technique does not appear to have been used elsewhere.

As Wintle (1980) pointed out a long time ago, luminescence dating of calcite presents difficulties. Although this reference relates specifically to speleothems, which are outside the terms of reference of the present review, the lack of publication in this area suggests that the same problems have been found to be common to other sources of calcite/aragonite.

TL has the handicap of spurious TL when dealing with calcium compounds (Hutton and Prescott, unpublished); optical dating may overcome this difficulty. Additionally the dosimetry of the deposit is difficult because of the radioactive "open" nature of the sediment.

Recently Singhvi et al. (1996) have suggested a new method for dating pedogenic carbonates which makes a virtue of necessity by exploiting "subtle changes in the natural field of a luminescent mineral after being trapped in a carbonate precipitate". It uses the entrapped "dirt" to date the carbonate precipitation; in the present case this "dirt" is quartz. If the dose rates from the carbonate and the host sediment are different, then the equivalent doses from the quartz in the carbonate and the host sediment will differ by an amount dependent on the time since the carbonate was formed. The first results from the Thar Desert show a large relative error in nominal TL ages from $2 \pm 1.3$ to $19.4 \pm 6.8 \mathrm{ka}$ but it could be fairly said that the method is demonstrated in principle.

An early attempt to obtain a TL age for Indian laterites by dating the auxiliary minerals gave ages of several hundred thousand years (Sankaran et al., 1985) but this work does not appear to have been followed up. In any case, the development of most laterite would generally be regarded as having taken place at times well beyond the present capacity of luminescence dating. Nevertheless, it is perhaps worth continuing effort.

Weathering is an essential element in the above examples. Weathering can also result in mobilisation of radioactive elements and may result in changes in the dose rate over time. This is further discussed in Section 10.6.

8.1.5. Impact craters. The shock excitation of mineral sediments by the impact of meteorites has the potential to reset the TL clock, either thermally or by pressure metamorphism. Sutton (1985a,b) found the TL age of the Arizona meteor crater to be $49 \pm 3 \mathrm{ka}$.

More recently, Miallier et al. (1997) have attempted to date an impact crater in the Sahara of Chad, using TL (and ESR) on quartz. The TL characteristics were quite atypical of quartz and did not lend themselves to the usual procedures for finding equivalent doses. Estimates led to ages greatly in excess of the presumed early- to midHolocene age. It may be that the impact had converted the quartz to coesite (Deer et al., 1982) in whole or in part. Nothing is known about the luminescence properties of this mineral specifically. Finding the age of past impact craters would appear to be an appropriate addition to the currently fashionable observation of extra-terrestrial objects likely to hit Earth.

8.1.6. Gypsum. With the advent of optical dating, we offer as an untapped suggestion, the possibility of using gypsum for luminescence dating. TL does not work because the gypsum decomposes on heating. There are large areas of gypseous lake deposits waiting to be evaluated.

\subsection{Earthquakes}

In $1984 \mathrm{Lu}$ Yanchou suggested to the authors (personal communication) that it should be possible to use TL to determine the age of palaeo-earth- 
quakes by dating the local expression of surface fault movements often associated with them. A vertical throw of some metres might not be uncommon. Immediately following the earthquake there would be a contour step, the low side of which would then become progressively filled with sediment, colluvial, aeolian or water laid. On the assumption that the infill process is sufficiently slow that the sediments have been exposed to sunlight long enough to reset the luminescence clock, it is then possible to use luminescence to date the infilling and hence find the time since at least the last previous earth movement. Knowledge of this time would contribute to the assessment of earthquake risk. Testing this suggestion on sites in China was not possible since suitable facilities were not available there at that time. Lu (personal communication) has subsequently reported TL dating of fine grains from an active fault site at Xiyangfang near Beijing.

The idea of using TL for seismic hazard evaluation was independently suggested by McCalpin (1986) as a result of sedimentological studies in the Bonneville Basin, Utah. Subsequently, Forman et al. (1989), in successfully evaluating TL as a technique for dating earthquake faults, found evidence for three major movements at $5.3 \pm 0.3,2.6 \pm 0.3$ and $0.5 \pm 0.2 \mathrm{ka}$ ago on the America Fork section of the Wasatch Fault in Utah. Forman et al. (1991) extended the technique to the Weber segment of the same fault.

Similarly, Porat et al. (1996), using IRSL, report movements of a fault near Eilat, Israel with a recurrence period of about $4 \mathrm{ka}$ from $37 \mathrm{ka}$ to modern times.

In a variation on the earthquake theme, Singhvi et al. (1994) reported a feasibility study on the possibility of using the thermal or hydrostatic stress imposed on fault "gouges" (sic) in the Kumaun Himalaya. The samples were apparently of unconsolidated material taken $0.5-1 \mathrm{~m}$ behind the exposed surface and were treated as sediments for the purposes of TL determinations. Clay mineralogy was used to estimate the temperature reached during the faulting but these results appear to us to be inconclusive. Ages of $38 \pm 8$ and $44 \pm 4$ ka were found for coarse and fine grains respectively at two distinct sites and these agree with a ${ }^{14} \mathrm{C}$ age of $\sim 50 \mathrm{ka}$ for a nearby lake, which straddles the fault and is presumed to be associated with it.

The foregoing fault movements were all in relatively active tectonic zones, near the edge of plates, and the value for earthquake hazard evaluation is fairly obvious. However, little is known about earthquakes in a-seismic, mid-plate, regions and few precautions have been taken when building major structures in such regions. Five of the only eleven historically recorded earthquakes that have produced surface ruptures in a-seismic areas have occurred in Australia. Hutton et al. (1994) have shown that the time of the last previous movement of the fault that produced the 1988 earthquake near Tennant Creek, Northern Territory (Mercali scale 6.7) was at least $50 \mathrm{ka}$ and probably above $70 \mathrm{ka}$ ago. The same authors assign an age in excess of $150 \mathrm{ka}$ for the creation of the Ash Ridge and Roopena scarps on Eyre Peninsula, South Australia, also in Archaean rocks.

Presumably, rock surfaces on which fault-generated slickenslides are visible will have been exposed to high stress, possibly sufficient to reset the TL clock. We have not been able to locate references to this in the literature. Technically this is not a "sediment" application but it seems to belong here.

It may be noted that Ikeya et al. (1982) had suggested using ESR for dating intra-fault materials. More recent work with ESR is summarised by Schwarcz (1994).

There appears to be considerable scope for earthquake hazard evaluation by luminescence dating. The matter surely has prospects for collaboration with the insurance industry.

\section{HOW OLD AND HOW YOUNG?}

It seems appropriate to include here some assessment of the effectiveness of luminescence methods in dating very "young" deposits and to discuss the present limits for finding "large" ages. For the purposes of this discussion "young" is taken to be less than $2 \mathrm{ka}$ and "old" greater than $200 \mathrm{ka}$. In fact, there is now a good collection of the former and rather few of the latter. We deal with the latter first.

\subsection{The old-the problem of fading}

Among the papers mentioned earlier, there are half a dozen references with examples of believable ages older than $200 \mathrm{ka}$ (Balescu and Lamothe, 1992; Duller, 1994a; Bryant et al., 1994; Pillans et al., 1996; Juyal et al., 1997). In addition there are two groups that can make a fair claim to match geologically determined ages towards $500 \mathrm{ka}$ and possibly further (Berger et al., 1992, 1994; Huntley et al., 1993a,b, 1994).

In discussing long-term dating, we shall take as a starting point the use of undifferentiated fine grains and separated feldspars. In an analysis of TL ages older than $\sim 100 \mathrm{ka}$, Berger $(1994,1995)$ concludes that feldspar mixtures are not ideal for such purposes. In such mixtures, the properties of individual grains may differ widely and, in particular, may have differing effective lifetimes.

In particular, as should already be clear from earlier sections, feldspars are liable to fading, both normal and anomalous, which leads to underestimates of the age when compared with independently validated ages. While this is a handicap at all ages, it is 


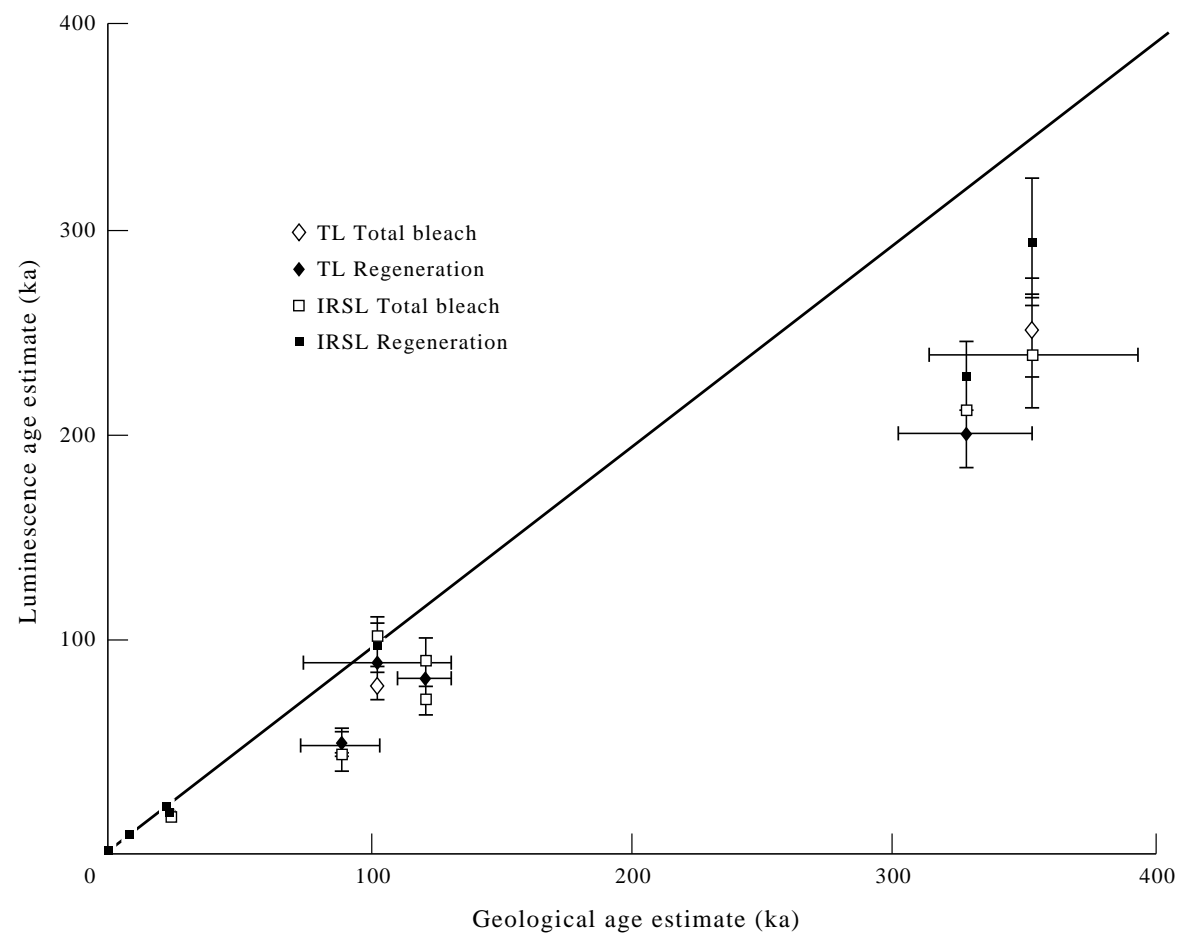

Fig. 7. Luminescence ages using feldspars from independently dated dune sites from the North Island, New Zealand, showing consistently low luminescence ages (after Duller, 1994a).

a critical issue for old sediments. This is illustrated by Fig. 7, taken from Duller (1994a), for potassium feldspars, a paper that was discussed earlier.

Accordingly, while the topic of fading is also discussed elsewhere in the present volume (Wintle, Duller), it is of such central importance to the practice of sediment dating that we shall now sketch the major issues.

Regardless of the particular dating method being used, i.e. TL or OSL, normal (thermal) fading is commonly dealt with by imposing one of a number of possible thermal annealing treatments, which have the effect of eliminating contributions from relatively shallow traps for which the excitation may overlap those from which the signal of interest originates. However, it is improbable that preannealing will eliminate traps subject to so-called anomalous fading.

Spooner (1992, 1993, 1994) has contributed significantly to the understanding of the management of samples containing feldspars by providing a better understanding of feldspar behaviour and the predictions that can be made as a consequence. This understanding is based on his own work and the earlier work of Visocekas on the characterisation of feldspars (set out in Visocekas et al. (1994) and in Visocekas and Zink (1995)).

In essence, the clear advice of Spooner and Visocekas is that anomalous fading cannot be circumvented by any existing laboratory procedure, such as preheating, because it is a quantum mechanical tunneling process and largely immune to thermal effects.
While fading is clearly associated with feldspars in general, it is not found in all of them, and effective dating may still be possible provided that monitoring is carried out. Such monitoring may, to paraphrase Spooner (1994), take the form of:

repeated [luminescence measurements] on stored portions of the sample [at intervals] over several orders of magnitude of time at $10^{\circ}$ and $100^{\circ} \mathrm{C}$; the resulting measurements should be plotted on a logarithmic time scale.

The criterion for acceptance of a sample is that the slope of a line through the data points does not differ statistically from zero. Failure of the test is a cause for rejection of the sample.

Spooner's own test data cover up to a full year and he remarks that this procedure is tedious and perhaps not practicable over such a length of time. Two months is described as an optimum time. He suggests an alternative: since the anomalous fading is due to quantum mechanical tunneling, it is accompanied by fading phosphorescence at liquid nitrogen temperature immediately after laboratory irradiation (Visocekas et al., 1994) and can be identified on this basis. Either way, identification of anomalous fading requires significant laboratory effort.

While fading is not confined to any particular part of the feldspar ternary diagram it becomes more likely with increasing calcium content (Akber and Prescott, 1985; Akber, 1986) and is least likely for the extreme end members of the alkali feldspar family (Spooner, 1993). If a low-potassium feldspar 


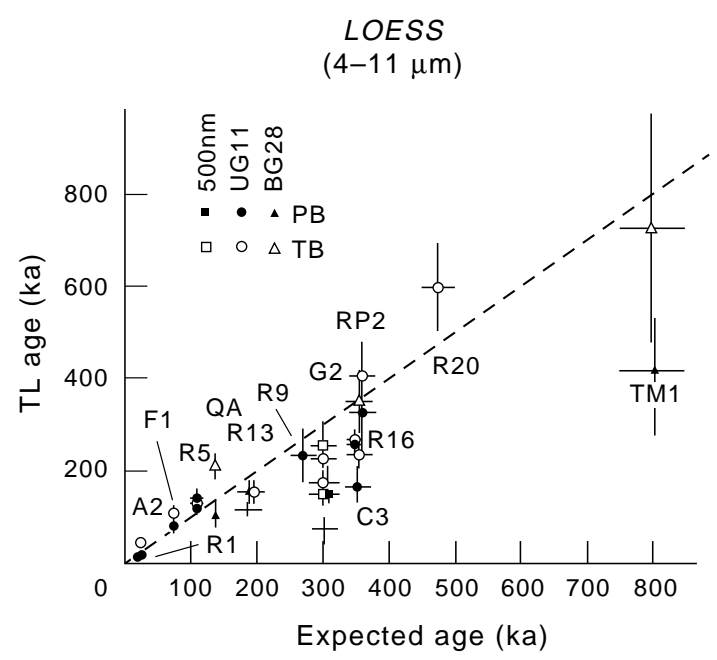

Fig. 8. Loess TL age vs. expected age from sites with independently established ages covering the timespan 20-800 ka. The broken line is a 1:1 correspondence of ages. A variety of protocols, as described in the text and indicated on the figure, was used. $\mathrm{TB}=$ total bleach; $\mathrm{PB}=$ partial bleach. Readout filters UG-11, BG28 and $500 \mathrm{~nm}$ are indicated; in addition, crosses indicate two ages obtained by PB-regeneration. The figure is based on Berger et al. (1992), updated from Berger et al. (1994). Samples: RTAT-1 (R1), AOK-2 (A2), FERY-1 (F1), RTAT-5 (R5), QTL-71A (QA), RTAT-13 (R13), RTAT-9 (R9), GRDQ-2 (G2), RTAT-16 (R16), CURL-3 (C3), RTP-2 (RP2), RTAT-20 (R20), TMUNA-1 (TM1).

turns out not to fade, there is a bonus that the dosimetry is simpler.

Thus, the choice of high-potassium feldspars, which can be separated by flotation with heavy liquids, would appear to be a useful first step in pushing the limit of luminescence dating backwards in time.

Since there is no confirmed evidence that quartz suffers from anomalous fading, it would appear to be another preferred dating material, although a preheat is needed to eliminate short-lived components after irradiation. The disadvantage for determination of large ages is that the signal saturates earlier than the best feldspars: it becomes non-linear at $30 \mathrm{~Gy}$ and usually saturates before $150 \mathrm{~Gy}$. The effective age limit may well be in the region 100 $200 \mathrm{ka}$, but older if the dose rate is low.

In the light of this, it is necessary to examine what appear to be the two most successful attempts so far to push age determinations in the direction of a million years (Berger et al., 1992, 1994; Huntley et al., 1993a,b, 1994).

\subsection{Measured ages-loess}

Berger et al. (1992, 1994) have carried out tests for TL ages using $4-11 \mu \mathrm{m}$ loess grains from New Zealand and Alaska measured against known-age deposits spanning the age range $20.2 \pm 1.6 \mathrm{ka}$ to $800 \pm 40 \mathrm{ka}$. Their 1992 paper is a summary of most of the material subsequently presented in considerable detail in the 1994 paper. We shall base our discussion primarily on the latter paper. Berger (1994) has also discussed this material.

The declared intention of these authors was to apply as wide a range as possible of dating protocols to this independently-dated set. A variety of different treatments was applied to fine grain loess samples from 18 sites. These treatments included additive dose, total bleach, partial bleach and partial bleach (regeneration) methods. The TL emission was viewed using one of UG11 (ultraviolet), BG28 (blue) or $500 \mathrm{~nm}$ (interference) filters, and there was a variety of optical bleaching and pre-readout heat treatments. Not all permutations of these variables were applied to all samples. On the basis of which procedures yield an age in accordance with expectation it was an objective of the work to draw conclusions about which methods are acceptable. In the circumstances, it should not be regarded as criticism that not all methods were successful.

One of the authors' requirements is that there should be an equivalent dose plateau, a requirement with which we agree. Among the 74 cases shown in their Table 4, a number displayed no equivalent dose plateau or it was ambiguous. Many of these 
came from samples where the regeneration method of analysis was used. Nevertheless, 41 cases yielded well-defined ages with stated errors.

Figure 8 reproduces Figure 3 of Berger et al. (1992) which we have updated by means of Berger et al. (1994). We have added material from the latter and taken the liberty of omitting two points that do not satisfy the plateau test (from QTL-71H, RTAT-13). Since the scale of Fig. 8 does not leave enough space for 12 ages between 20.5 and $26.5 \mathrm{ka}$, these are merely indicated on the figure. However, none of this group of ages lay within one standard deviation of expectation. As the authors pointed out, all but three were low, mostly by a substantial fraction; and they attribute this to modification of the deposits by incorporation of other material subsequent to the original deposition. They appear to have been just plain unlucky with their low-age sites.

Examination of Fig. 8 shows that there appears to be only limited common ground among the methods used in finding ages that match expectation. Total bleach (open symbols in Fig. 8) may well be preferable for ages above $300 \mathrm{ka}$, but there appears to be little to choose between total bleach and partial bleach (solid symbols) in the age range below $300 \mathrm{ka}$.

It does not seem possible to conclude (as the authors do) that recording with blue emission (BG28 filter, triangles) is to be preferred to ultraviolet (UG11 filter, circles), for samples of any age. So far as the use of $500 \mathrm{~nm}$ (squares) as an observ-

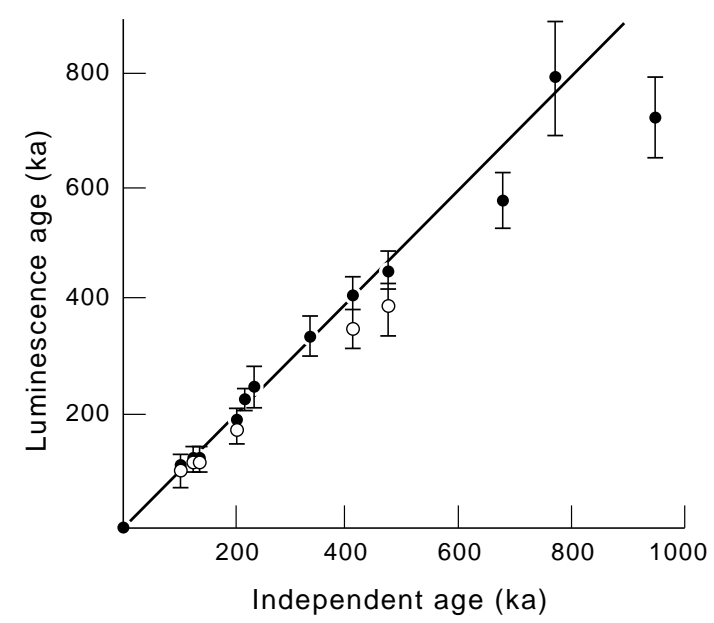

Fig. 9. TL ages for the fossil dune system from the southeast of South Australia. The figure contains all the ages given in Huntley et al. (1993a,b, 1994), including zero age determinations on modern samples from the same sequence. The solid circles are TL ages for $100 \mu \mathrm{m}$ quartz, the open circles are from IRSL for inclusions within the same grains. A group of five ages plotted schematically at $\sim 120 \mathrm{ka}$ covers the observed age range $114-132 \mathrm{ka}$. The luminescence ages are plotted against ages independently derived on geological grounds by Belperio (1995) who identified the ranges with oxygen isotope stages. The diagonal line shows a 1:1 age correspondence. ing wavelength is concerned, there are not enough samples to draw a conclusion.

Berger et al. make the interesting suggestion that an age determination less than $300 \mathrm{ka}$ may be acceptable if partial bleach and total bleach methods give the same answer, but there do not appear to be enough examples to establish this, one way or the other.

Figure 8 shows that a number of their age determinations on loess have been successful in yielding ages in agreement with independent ages and that these extend to about $800 \mathrm{ka}$. There is, in our view, still not a demonstrably consistent methodology that will yield reliable ages for loess over this age range. There is an earnest of success but further work is clearly called for.

\subsection{Measured ages-quartz}

As described in Section 2.3 on comparisons, a suite of ages has been found by coarse grain quartz TL for a sequence of ranges which run roughly parallel with the coast in the south-east of South Australia (Huntley et al., 1993a,b, 1994).

In summary, they represent relict sand dunes left behind on a slowly rising land surface by successive interglacial incursions of the sea at roughly $120 \mathrm{ka}$ intervals. Comparison with ages established on independent geological grounds allows a test of quartz TL ages that is believable back to $500 \mathrm{ka}$. Older than that, the data by the same procedures sometimes fail to produce an age. However, ages near the Brunhes-Matuyama reversal $(780 \mathrm{ka})$ are obtained, though with limited accuracy (Fig. 9).

In a piece of serendipity, Huntley et al. (1993b) found that IRSL can be detected from the same "quartz" extracts that were used for TL. Since pure quartz does not respond to IR (it is commonly used as a test for purity of separation) it was concluded that there are inclusions within the quartz and these were supposed to be feldspar (although other minerals are also known to occur as inclusions). IRSL ages were obtained for some of the same dunes as were dated by TL.

We have plotted all published ages from this dune system in Fig. 9. In this figure the luminescence age is plotted against the age of the corresponding dune as determined on geological grounds by Belperio (1995). Belperio allocated each dune to an oxygen isotope stage, from which the age itself follows. In Fig. 9 these ages come from the $\delta^{18} \mathrm{O}$ record of Shackleton et al. (1990). The points are plotted at the age corresponding to the largest value of $\delta^{18} \mathrm{O}$ for the stage in question. The numerical values of these ages differ slightly from those of Belperio, who used the isotope chronology of Williams et al. (1988) adjusted for the BrunhesMatutyama boundary from Spell and McDougall (1992). 
The TL ages are in good agreement with expectation, apart from the point at the TL age of $720 \mathrm{ka}$. This dune is tentatively assigned to isotope stage 25 by Belperio, which sets its age at about $950 \mathrm{ka}$. It is tempting to interpret the evident mismatch of this pair of TL and expected ages as a signal to recheck the field evidence for either the identity of the sample or the identity of the dune.

IRSL ages are found to correspond correctly to $\delta^{18} \mathrm{O}$ stages back to $200 \mathrm{ka}$ (Huntley et al., 1993b), although a trend to be low can be discerned. Beyond $400 \mathrm{ka}$, work in progress (Huntley, personal communication) shows that IRSL ages fall consistently below the geological ages. This is consistent with fading, as might be expected if the inclusions are feldspar.

So far as the quartz TL results are concerned, two features made it possible to find ages as old as these, notwithstanding the normal tendency of quartz to saturate. These are: (i) the dose rates are very low, of the order of $0.5 \mathrm{~Gy} \mathrm{ka}^{-1}$ and (ii) the growth curve continues to rise quasi-linearly at large doses (say beyond $300 \mathrm{~Gy}$ ) so that the additive/regenerative dose curves can be matched. The exact reason for the rise at large doses is not known.

Dutkiewicz and Prescott (1997) show quartz growth curves with the same behaviour. Although geographically remote from those just discussed, some of their samples could have been derived from the same original source material.

Chawla et al. (1992) have also found similar high dose behaviour in quartz samples from the Thar desert. They have not sought to find ages from doses in this region of the growth curve. However, they find the same sort of mismatch between additive and regenerative data as found by Huntley et al. (1993b) and it plausibly has the same interpretation.

\subsection{Old samples—summary}

For those wanting to use luminescence dating in the 0.3-1 Ma region, the best advice may be to use total bleach TL on quartz, or TL/IRSL on high-K feldspar if lack of fading has first been confirmed. A low dose rate would help.

Furthermore, a better understanding of the luminescence physics of quartz and feldspars is needed before luminescence dating can be confidently extended to beyond $500 \mathrm{ka}$ and subsequently to $1 \mathrm{Ma}$.

\subsection{The young}

At the young end of the time-scale, ages less than 1000 years are easily measurable for sediments and, under favourable conditions, zero age to perhaps a 100-year 2-sigma limit. On this time-scale lumines- cence dating, particularly optical dating, may well prove superior to ${ }^{14} \mathrm{C}$ because of calibration uncertainties for radiocarbon in this time period.

In measuring young ages, fading may be less of a problem and the essential question is whether there is enough signal to provide a good signal-to-noise ratio. In sediment dating where the zeroing agent is bleaching but the readout procedure involves heating, there is always a significant residual on which the signal of interest is superimposed. This is the case even when exposure to light is prolonged (see also McKeever, this volume). An exception is the rapidly-bleaching peak in quartz, which is itself reduced to an effective zero, although it may be sitting on the shoulder of the slowly-bleaching peak (e.g. Franklin et al. (1995), their Figure 4(b)).

Whether an age can be found depends not only on the size of the residual but also on whether the sample is bright enough and the equipment sensitive enough for the signal to be separated from it. Feldspars should be better than quartz for this purpose but they lack rapidly bleaching peaks (Robertson et al., 1991, 1993) and this is likely to limit the lowest age achievable by TL for them. In either case, it is obvious that environments with high dose rates will be easier to date than those with low dose rates.

An example of a near-zero age determination by thermoluminescence (as distinct from OSL) is to be found in the paper by Ollerhead et al. (1994) where the age is compared with that obtained using IRSL dating of the same samples of potassium feldspar from Buctouche Spit, New Brunswick, in the age range 0-1 ka. Smith et al. (1997) have obtained TL ages of $0.00 \pm 0.06 \mathrm{ka}$ using selective bleach and $0.13 \pm 0.04 \mathrm{ka}$ using total bleach for a surface sample of quartz in central Australia.

Optical dating is largely immune to the problem of residuals. The zeroing process by light removes virtually all the electrons from the traps from which the OSL signal comes; and the signal on which the age determination is based is superimposed on a negligible or very low residual. Even if the natural light bleaching exposure was not enough to completely remove all electrons from some traps, optical stimulation does not interrogate these so that they do not add to the background. This applies both to GLSL and IRSL. In these cases, the small amount of residual will be of concern only to those pushing for ages very close to zero.

An important reservation should be voiced here. Preheating may cause thermal transfer of electrons into those trap(s) giving rise to OSL from a trap or traps not directly involved. Some of these retrapped electrons contribute to the OSL signal. The importance of this extra contribution depends on the particular circumstances but a scenario in which it could easily distort the outcome would involve a young sediment which has been exposed to enough light to reset the (easily bleached) OSL source levels 
Table 2. Comparison between luminescence and ${ }^{14} \mathrm{C}$ dates

\begin{tabular}{|c|c|c|c|c|c|c|c|}
\hline Sample & $\begin{array}{l}\text { Depth } \\
\text { (m) }\end{array}$ & $\begin{array}{l}D_{\mathrm{e}}^{\mathrm{b}} \\
(\mathrm{Gy})\end{array}$ & $\begin{array}{l}\text { Dose rate } \\
\left(\mathrm{mGy} \mathrm{yr}^{-1}\right)\end{array}$ & $\begin{array}{c}\text { Luminescence } \\
\text { date }(\mathrm{yr})\end{array}$ & Rand. & $\begin{array}{l}\text { Total } \\
\text { ty }\end{array}$ & $\begin{array}{l}{ }^{14} \mathrm{C} \text { date }^{\mathrm{a}} \\
(\mathrm{yr} \mathrm{BP})\end{array}$ \\
\hline $939007^{c}$ & 0.045 & $0.40 \pm 0.04$ & $4.01 \pm 0.15$ & 100 & 11 & 13 & \multirow{2}{*}{$\begin{array}{l}270 \pm 80 \\
370170\end{array}$} \\
\hline 938001 & 1.1 & $1.07 \pm 0.05$ & $3.57 \pm 0.11$ & 300 & 16 & 25 & \\
\hline 938002 & 1.3 & $2.11 \pm 0.14$ & $3.67 \pm 0.14$ & 580 & 40 & 50 & \\
\hline 938003 & 2.4 & $3.53 \pm 0.10$ & $3.57 \pm 0.08$ & 990 & 30 & 70 & \\
\hline 938004 & 2.8 & $4.51 \pm 0.14$ & $3.41 \pm 0.07$ & 1320 & 50 & 90 & \\
\hline 938006 & 5.3 & $6.55+0.14$ & $3.41 \pm 0.11$ & 1920 & 70 & 130 & $2010 \pm 210$ \\
\hline
\end{tabular}

After Murray (1996).

${ }^{a}$ Calibrated ages of $300(150-430), 345$ (310-510) and 1940 (1700-2300) years BP, where the ranges given in parentheses are at 1 sigma (Stuiver and Reimer, 1993). The oldest date (by AMS) was on fine disseminated charcoal, the younger dates used larger discrete pieces of charcoal.

${ }^{\mathrm{b}} D_{\mathrm{e}}$ and dose rate uncertainties are one standard error on the mean (i.e. random component only).

c 938007 includes a cosmic dose rate of $0.31 \mathrm{mGy} \mathrm{yr}^{-1}$, rather than the $0.17 \mathrm{mGy} \mathrm{yr}^{-1}$ used for all other samples, and the gamma dose has been reduced by $35 \pm 5 \%$.

but not enough to empty all levels. The effect may be seen when a non-zero readout may be found, after preheating, for a sample previously bleached to zero. In general, the relative importance of the effect will be greatest for very young samples.

This effect was first noted by Huntley et al. (1985) in their seminal OSL paper. Since then, it is mostly papers from the Huntley stable which have taken it into account: Godfrey-Smith et al. (1988); Huntley et al. (1993b); Ollerhead et al. (1994); Lian et al. (1995); Huntley and Clague (1996). The last of these references gives a contemporary account of the effect and corrections to be applied for it. A similar approach was reported by Rhodes and Pownall (1994).

Table 2, which is reproduced from Murray (1996), shows that ages in the range 0-2 ka are measurable by OSL and phototransferred luminescence of quartz with a precision of better than $10 \%$. Murray is discussing water-laid flood deposits from Tuggeranong Creek, a tributary of the Murrumbidgee River near Canberra.

Other examples of young ages from differing geomorphological environments are: IRSL ages for Holocene Mojave Desert aeolian sands (Wintle et al., 1994), Buctouche Spit, already mentioned above (Ollerhead et al., 1994), Canadian inland Holocene sand dunes (Wolfe et al., 1995), NW England coastal dunes (Pye et al., 1995) and Tsunami deposits (Huntley and Clague, 1996).

Explicit discussion of low-age dating is found in papers by Berger (1995), Murray (1996) and Duller (1996b).

\section{PERSPECTIVES, PROBLEMS AND PROSPECTS}

It seems appropriate to set out in summary form some of the issues that appeal to us as relevant to the actual practice of luminescence dating of sediments.

\subsection{Validation}

It is clear that there is still a great deal of empiricism, not to say necromancy, in the approach to luminescence dating. We recall the quotation from Macbeth with which this paper began. There is a tendency to say, "Let's try method A or method B and if it gives the age we expect, then let's use it". To do this one has to have an independent and trustworthy age with which to compare the luminescence age. It may well be argued that if you already know what that age is, then there seems little point in doing luminescence dating at all! The justification is that you, and others, will have enough confidence to be able to use the method again in the future in circumstances for which no comparison exists.

There is something unsatisfying in picking out a handful of correct ages from a large array of incorrect ones. In the last analysis, confidence in applying luminescence dating and believing the results depends ultimately on understanding the physical characterisation of the properties of the minerals.

However, there will always be a case for comparisons among dating methods. The time has not yet come when luminescence dating alone can be relied upon for ages from zero to a million years in any arbitrary environment, wet or dry. So, where should we be most confident and where most cautious?

\subsection{Zeroing}

After heating there is rarely any doubt about whether the luminescence signal was set to zero. However, resetting to zero is by no means certain when the mechanism is bleaching by exposure to light. The article on methodology (Wintle, this volume) describes various protocols designed to overcome this uncertainty.

The general features of bleaching have long been known and were discussed, for TL, by Wintle and Huntley (1982) in their original work and were compactly expressed in their requirement that a dat- 
ing method should give zero age for recently deposited material from the same sequences. This is still a prime requirement for all protocols.

While it is the behaviour in the field that matters in the long run, laboratory bleaching studies of the materials used for dating have been of obvious relevance. In summary, such studies show that TL at all glow-curve temperatures for both quartz and feldspar (and mixtures of them) is reduced to a stable, low, but not zero level in times of the order of $24 \mathrm{~h}$ of full sun. It is necessary to determine what this level is in order to carry out quality dating.

Bleaching of the $325^{\circ} \mathrm{C}$ TL peak of quartz to an essentially zero level takes place in tens of seconds in laboratory samples and in no more than minutes in surface samples in open field conditions, where the grains may not be laid out in single layers and may have a surface coating that attenuates solar radiation. OSL in quartz is almost certainly from the rapidly bleached level or levels. Thus, GLSL, or one or other of the selective bleach TL protocols that exploit this level, will give ages that are least subject to uncertainty about the degree of bleaching.

Bleaching of the infrared stimulated component is perhaps a special case. It is zeroed (with differing effectiveness) by all incident wavelengths but notably at the resonance around $880 \mathrm{~nm} / 1.4 \mathrm{eV}$, the same photon energy that is used for readout. There are implications for collecting and laboratory handling of samples for IRSL.

There is field evidence from many places that virtually complete zeroing can occur. Most open sites subject to frequent sunlight would qualify if they also satisfy the criterion of zero luminescence for zero age. The protocol used can then be the total bleach method, with allowance for the residual TL. This applies to quartz, separated feldspar and undifferentiated fine grains.

In other cases there is clear evidence that zeroing has been incomplete and/or there is an expectation to that effect. In such cases the partial bleach method and its variations, which restrict the measurement of TL light to that fraction which is most easily bleached, are appropriate. It can be applied to any of the materials currently extracted for dating.

One should be wary of sediments deposited by or under water or in heavy shade, since they are those most subject to uncertainty in the degree of resetting. Apart from uncertainty in the environment before the sediment grains entered the water, water itself attenuates the most effective wavelengths and this increases with increasing depth of the water column. A heavy burden of sediment causes selfscreening. OSL with partial bleach is the preferred protocol, together with thoughtful attention to the procedures to use in laboratory bleaching with the aim of emulating natural conditions.
We can offer little encouragement for routine dating of glacial and fluvioglacial deposits. This is still a research area.

\subsection{Fading}

If feldspars or undifferentiated fine grain mixtures are used, it must be assumed that some of the signal may be subject to fading. This was discussed at length in Section 9.1, where it is stated that the quality of such ages can be improved by imposing a preheating procedure. While this empties relatively shallow traps it does not eliminate the effect of traps subject to anomalous fading.

Following Visocekas and Spooner (see Section 7), we contend that anomalous fading cannot be circumvented by any existing laboratory procedure, preheating in particular. It follows that dating procedures should include specific tests to identify anomalous fading. These may take the form of a direct test for fading itself or detection of the postirradiation phosphorescence associated with tunneling. Selection of high-K feldspars improves the probability of avoiding fading.

Further physics-based research into the causes of fading and methods of coping with it is called for.

Since there is no confirmed evidence that quartz suffers from anomalous fading, it would appear to be a preferred dating material, although a preheat is needed to eliminate short-lived components of the glow curve after irradiation. The disadvantage of quartz for determination of large ages is that it saturates earlier than the best feldspars.

\subsection{Generating the data}

Among the choices to be made in finding the equivalent dose is the question of the wavelength at which observations are made. Good cases can be made for all the following recommendations:

1. TL of quartz, total bleach: $375^{\circ} \mathrm{C}$ peak, $470 \mathrm{~nm} /$ $2.6 \mathrm{eV}$

2. TL of feldspar or mixtures, total bleach: $410 \mathrm{~nm} /$ $3.0 \mathrm{eV}$ (do not use ultraviolet $<320 \mathrm{~nm} / 3.9 \mathrm{eV}$ )

3. TL of quartz, partial or selective bleach: $325^{\circ} \mathrm{C}$ peak, $400 \mathrm{~nm} / 3.1 \mathrm{eV}$

4. GLSL on quartz: $370 \mathrm{~nm} / 3.35 \mathrm{eV}$

5. GLSL on feldspar or mixtures: $410 \mathrm{~nm} / 3.0 \mathrm{eV}$ (do not use ultraviolet $<320 \mathrm{~nm} / 3.9 \mathrm{eV}$ )

6. IRSL on feldspar or mixtures: $410 \mathrm{~nm} / 3.0 \mathrm{eV}$ (do not use ultraviolet $<320 \mathrm{~nm} / 3.9 \mathrm{eV}$ )

Not enough is known about red emissions to be able to make a useful recommendation, except to identify it as a useful topic for research.

While not all dating laboratories have access to the necessary facilities, there is much to be said for routine spectral measurements of the kind described 
by Krbetschek et al. (this volume) as part of the measurements for actual dating.

Single aliquot analyses have been developed to reduce the variability between nominally identical aliquots of the same sample and to assess and allow for the possibility that older (or younger) materials have been incorporated into the sample, thereby distorting its age. This protocol has now been sufficiently developed that it can be recommended. It is a mistake to suppose that it saves time if its full value is to be exploited. It clearly works well on samples with linear dose responses. Whether it has limitations at very small or very large ages, where growth curves may be non-linear, has still to be demonstrated.

The single grain variant is still under development and awaits further research.

\subsection{Aspects of data analysis}

There is a substantial body of literature in which the additive dose analysis procedure is compared with the regeneration procedure and their relative merits adduced. Often, regeneration gives a smaller value than additive dose and this is interpreted as evidence of a change in sensitivity with bleaching, which forms part of the latter. Additive dose is then preferred.

We have no difficulty with the idea of using differing measurement techniques for differing age ranges or for differing classes of samples. We accept that differing methods of analysis of the data may apparently give differing ages but we do not agree that one should be ipso facto preferred to the other.

Suppose, for the sake of argument, that OSL or $\mathrm{TL}$, or whatever, is systematically affected by fading. This will have an impact on all the data collected, regardless of the method of analysis subsequently used. If, then, the additive dose procedure gives "correct" ages while the regeneration method does not, it is at least open to argument that regeneration has not been correctly applied or that the "correct" additive age is the product of two compensating errors. We are inclined to discount (respectfully) many of the conclusions drawn from comparisons of additive and regeneration analyses.

We wish to restate a philosophy, first stated by Readhead (1982, 1988) and further developed in the Adelaide and Simon Fraser laboratories, intended to reconcile these differences.

The use of additive dose makes an assumption about the mathematical model to use for the necessary extrapolation of the growth curve. It is commonly, but not always, assumed to be a saturating exponential. For samples approaching saturation the extrapolation is perilous in the extreme and the scope for error is disquieting.
The shape of the "missing" part of the growth curve is conveniently provided, without assumptions about the actual model, by the same set of measurements as is needed for the regeneration method. The two methods can be combined in what has been called the "Australian Slide" method (Prescott et al., 1993). This procedure fits a curve to the regeneration data statistically, then "slides" it along the dose axis until a best fit is obtained with the additive dose data. Tests of the fit are carried out to see if there was a significant sensitivity change in the former; and then the two sets of data are fitted jointly to give an estimator for the dose shift. Correction for residual luminescence is an option, as is the choice of fitting function and the acceptance, or otherwise, of a correction for sensitivity change.

We make no apology for this advocacy, for the reasons given in the original reference. When we use it, we also estimate the factor that expresses the change in sensitivity after bleaching. If it does not differ statistically from unity we set it to unity and reprocess the data. If not, we reject the data set.

However, some might find it acceptable to correct for the apparent sensitivity change in the use of the Australian Slide method because the sensitivity factor is estimated objectively as part of the procedures.

\subsection{Dose rates}

With dating limits being pushed ever further back, a time profile of the environmental radiation giving rise to the stored luminescent energy needs to be constructed. The water content may not have been constant and the sediment may have become compacted. These, and mobility of relevant radionuclides, particularly down the profile of the sediment, may make the dose rate a variable function of time. The contribution of cosmic rays to the dose rate needs to be added, although it is usually small. For long sequences, or for shallow accumulating sequences, the cosmic ray dose rate has not remained constant.

Particularly at wet sites, radioactive disequilibrium must also be considered. Redundant determinations of dose rate, by more than one technique, should give this information but are useful in any case. If one of them is field scintillometry, carried out at the time of sample collection, little extra time is necessary and a completely independent estimate of dose rate is obtained. High-resolution gamma and alpha spectrometry give more detailed information about disequilibrium but are time-consuming and/or expensive.

In summary, equilibrium should never be assumed in luminescence dating and disequilibrium is almost guaranteed in wet environments, including those that were wet in the past. For any but very 
simple environments, a dose rate history should always be determined, wet or dry.

\subsection{Telling the world}

On the matter of presentation of results, we strongly suggest that workers follow the excellent example of Huntley in the way in which luminescence ages are reported. Such practice follows the original suggestions of Wintle and Huntley (1982). This means the showing of dose curves, glow curves and $D_{\mathrm{e}}$ plateaux for all TL ages; and dose curves, depletion curves and time plateaux for OSL. Zero age samples should be included in the test programme and should return zero age. There should be redundancy in dose rate determinations. Such practices are well exhibited in Lian et al. (1995), which we commend.

Acknowledgements - We are particularly grateful to D. J. Huntley, M. A. Williams and A. G. Wintle for critical readings of the manuscript. We are very appreciative of the many people who replied to our request for reprints. We could not quote all of them but they gave us a lot of interesting reading. The work was supported by the Archaeometry Special Fund of the Department of Physics and Mathematical Physics of the University of Adelaide.

\section{REFERENCES}

Abeyratne, M., Spooner, N. A., Grün, R. and Head, J. (1997) Multidating studies of Batadomba Cave, Sri Lanka. Quat. Sci. Rev. (Quat. Geochron.) 16, 243255.

Aitken M. J. (1987) Archaeometrical dating. In: Chronologies in the Near East (eds Aurenche O., Evin J. and Hours F.), pp. 207-216. British Archaeological Reports, International Series, Vol. 379.

Aitken, M. J. and Xie, J. (1992) Optical dating using infrared diodes: young samples. Quat. Sci. Rev. 11, $147-152$.

Akber, R. A. (1986) Materials and techniques for thermoluminescence dating, pp. 110-113. Ph.D. thesis, University of Adelaide.

Akber, R. A. and Prescott, J. R. (1985) Thermoluminescence in some feldspars: early results from studies of spectra. Nucl. Tracks 10, 575-580.

Balescu, S. and Lamothe, M. (1992) The blue emission of $\mathrm{K}$-feldspar coarse grains and its potential for overcoming TL age underestimation. Quat. Sci. Rev. 11, $45-51$.

Bassinot, F. C., Labeyrie, L. D., Vincent, E., Quidelleur, X., Shackleton, N. J. and Lancelot, Y. (1994) The astronomical theory of climate and the age of the Brunhes-Matuyama magnetic reversal. Earth Planet. Sci. Lett. 126, 91-108.

Bell, W. T. (1978) Studies in thermoluminescence dating in Australia. Ph.D. thesis, Australian National University, Canberra.

Bell, W. T. (1991) Thermoluminescence dates for the Lake Mungo aboriginal fireplaces and the implications for radiocarbon dating. Archaeometry 33, 43-50.

Belperio A. P. (1995) Quaternary. In: The Geology of South Australia. Vol 2, The Phanerozoic (eds Drexel, J. F and Preiss W. V.), pp. 222-226. South Australia. Geol. Survey Bull., Vol. 54.
Berger, G. W. (1988) TL dating studies of tephra, loess and lacustrine sediments. Quat. Sci. Rev. 7, 295-303.

Berger, G. W. (1991) The use of glass for dating volcanic ash by thermoluminescence. J. Geophys. Res. 96, 19705-19720.

Berger, G. W. (1992) Dating volcanic ash by use of thermoluminescence. Geology 20, 11-14.

Berger, G. W. (1994) Thermoluminescence dating of sediments older than $\sim 100 \mathrm{ka}$. Quat. Geochron. (Quat. Sci. Rev.) 13, 445-455.

Berger, G. W. (1995) Progress in luminescence dating methods for Quaternary sediments. In: Dating Methods for Quaternary Deposits (eds Rutter, N. W. and Catto, N.R.), pp. 81-104. Geological Association of Canada.

Berger, G. W. and Anderson, P. M. (1994) Thermoluminescence dating of an Arctic lake core from Alaska. Quat. Geochron. (Quat. Sci. Rev.) 13, 497501.

Berger, G. W. and Busacca, A. J. (1995) Thermoluminescence dating of late Pleistocene loess and tephra from eastern Washington and southern Oregon and implications for the eruptive history of Mount St. Helens. J. Geophys. Res. 100, 2236122374.

Berger, G. W. and Easterbrook, D. J. (1993) Thermoluminescence dating tests for lacustrine, glaciomarine, and floodplain sediments from western Washington and British Columbia. Can. J. Earth Sci. 30, 18151828.

Berger, G. W., Clague, J. J. and Huntley, D. J. (1987) Thermoluminescence dating applied to glaciolacustrine sediments from central British Columbia. Can. J. Earth Sci. 24, 425-434.

Berger, G. W., Huntley, D. J. and Stipp, J. J. (1984) Thermoluminescence studies of ${ }^{14} \mathrm{C}$ dated marine core. Can. J. Earth Sci. 21, 1145-1150.

Berger, G. W., Luternauer, J. L. and Clague, J. J. (1990) Zeroing tests and application of thermoluminescence dating to Fraser River delta sediments. Can. J. Earth Sci. 27, 1737-1745.

Berger, G. W., Pillans, B. J. and Palmer, A. S. (1992) Dating loess up to $800 \mathrm{ka}$ by thermoluminescence. Geology 20, 403-406.

Berger, G. W., Pillans, B. J. and Palmer, A. S. (1994) Test of thermoluminescence dating of loess from New Zealand and Alaska. Quat. Sci. Rev. 13, 309-333.

Berger, G. W., Pewe, T. L., Westgate, J. A. and Preece, S. J. (1996) Age of Sheep Creek tephra (Pleistocene) in Central Alaska from thermoluminescence dating of bracketing loess. Quat. Res. 45, 263-270.

Bruins, H. J. and van der Plicht, J. (1996) The Exodus enigma. Nature 382, 213-214.

Bryant, E. A., Young, R. W. and Price, D. M. (1992) Evidence of Tsunami sedimentation on the southeastern coast of Australia. J. Geol. 100, 753-765.

Bryant, E. A., Young, R. W., Price, D. M. and Short, S. A. (1994) Late Pleistocene dune chronology: nearcoastal New South Wales and eastern Australia. Quat. Sci. Rev. 13, 209-223.

Chawla, S., Dhir, R. P. and Singhvi, A. K. (1992) Thermoluminescence chronology of sand profiles in the Thar desert and their implication. Quat. Sci. Rev. 11, 25-32.

Clarke, M. L. (1994) Infra-red stimulated luminescence ages from aeolian sand and alluvial fan deposits from the eastern Mojave desert, California. Quat. Geochron. (Quat. Sci. Rev.) 13, 533-538.

Clarke, M. L., Richardson, C. A. and Rendell, H. M. (1995) Luminescence dating of Mojave Desert sands. Quat. Sci. Rev. 14, 783-789.

David, B., Roberts, R., Tuniz, C., Jones, R. and Head, J. (1997) New optical and radiocarbon dates from 
Ngarrabullgan cave, a Pleistocene archaeological site in Australia: implications for the comparability of time clocks and for the human colonization of Australia. Antiquity 71, 183-188.

Dawson, A. G., Hindson, R., Andrade, C., Freitas, C., Parish, R. and Bateman, M. (1995) Tsunami sedimentation associated with the Lisbon earthquake of 1 November AD 1755: Boca do Rio, Algarve, Portugal. The Holocene 5, 209-215.

Deer W. A., Howie R. A. and Zussman J. (1982) An Introduction to the Rock-forming Minerals, pp. 341 and 351. Longman, Harlow, UK.

Dreimanis, A., Hütt, G., Raukas, A. and Whippey, P. W. (1978) Dating methods of Pleistocene deposits and their problems 1 . Thermoluminescence dating. Geoscience Canada 5, 55-60.

Duller, G. A. T. (1991) Equivalent dose determination using single aliquots. Nucl. Tracks 18, 371-378.

Duller, G. A. T. (1994a) Luminescence dating using feldspars: A test case from southern North Island New Zealand. Quat. Geochron. (Quat. Sci. Rev.) 13, 423427.

Duller, G. A. T. (1994b) Luminescence dating of poorly bleached sediments from Scotland. Quat. Geochron. (Quat. Sci. Rev.) 13, 512-524.

Duller, G. A. T. (1996a) The age of the Koputaroa dunes, North Island, New Zealand. Palaeogeogr., Palaeoclimatol., Palaeoecol. 121, 105-114.

Duller, G. A. T. (1996b) Recent developments in luminescence dating Quaternary sediments. Prog. Phys. Geogr. 20, 127-145.

Duller, G. A. T., Wintle, A. G. and Hall, A. M. (1995) Luminescence dating and its application to key prelate Devensian sites in Scotland. Quat. Sci. Rev. 14, 495-519.

Dutkiewicz, A. and Prescott, J. R. (1997) Thermoluminescence ages and palaeoclimate from the lake Malata-Lake Greenly complex, Eyre Peninsula, South Australia. Quat. Sci. Rev. (Quat. Geochron.) 16, 367-385.

Edwards, S. R. (1993) Luminescence dating of sand from the Kelso Dunes, California. In: The Dynamics and Environmental Context of Aeolian Sedimentary Systems (ed. Pye, K.), Geological Society, London, Special Publication 72, 59-68.

Forman, S. L. and Ennis, G. (1992) Limitations of thermoluminescence to date waterlain sediments from glaciated fiord environments of western Spitsbergen, Svalbard. Quat. Sci. Rev. 11, 61-70.

Forman, S. L., Machette, M. N., Jackson, M. E. and Maat, P. (1989) An evaluation of thermoluminescence dating of paleoearthquakes on the American Fork segment, Wasatch fault, Utah. J. Geophys. Res. 94, $1622-1630$.

Forman, S. L., Nelson, A. R. and McCalpin, J. P. (1991) Thermoluminescence dating of faultscarp-derived colluvium: deciphering the timing of paleoearthquakes on the Weber segment of the Wasatch Fault zone, north central Utah. J. Geophys. Res. 96, 595-605.

Forman, S. L., Pierson, J., Smith, R. P., Hackett, W. R. and Valentine, G. (1994) Assessing the accuracy of thermoluminescence for dating baked sediments beneath late Quaternary lava flows, Snake River Plain, Idaho. J. Geophys. Res. 99, 15569-15576.

Franklin, A. D., Prescott, J. R. and Scholefield, R. B. (1995) The mechanism of thermoluminescence in an Australian sedimentary quartz. J. Lumin. 63, 317326.

Gaigalas, A. and Hütt, G. (1996) OSL dating of the Merkine (Eem) interglacial (in Jonionys) and the Nemunas glaciation (Rokai Section) in Lithuania. PACT 50-I.7, 59-69.
Gemmell, A. M. D. (1988a) Thermoluminescence dating of glacially transported sediments: some considerations. Quat. Sci. Rev. 7, 277-285.

Gemmell, A. M. D. (1988b) Zeroing of the signal in sediment undergoing fluvioglacial transport, an example from Austerdalen, western Norway. Quat. Sci. Rev. 7, 339-345.

Gemmell, A. M. D. (1994a) Environmental controls on the TL age of modern (zero-age) proglacial outwash sediments. Quat. Geochron. (Quat. Sci. Rev.) 13, 485-489.

Gemmell, A. M. D. (1994b) Thermoluminescence in suspended sediment of glacier meltwater streams. J. Glaciol. 40, 158-166.

Gemmell, A. M. D. (1997) Fluctuations in the thermoluminescence signal of suspended sediment in an Alpine glacial meltwater stream. Quat. Sci. Rev. (Quat. Geochron.) 16, 281-290.

Godfrey-Smith, D. I., Huntley, D. J. and Chen, W.H. (1988) Optical dating studies of quartz and feldspar sediment extracts. Quat. Sci. Rev. 7, 373-380.

Guérin, G. and Valladas, G. (1980) Thermoluminescence dating of volcanic plagioclases. Nature 286, 697-699.

$\mathrm{Hu}$ Biru and Lu Yanchou (1985) Composition of Loess. I. Grain-size distribution. In: Loess and the Environment (eds Liu Tungsheng et al. [sic]), pp. 93-98. China Ocean Press, Beijing.

Huntley, D. J. and Clague, J. J. (1996) Optical dating of tsunami-laid sands. Quat. Res. 46, 127-140.

Huntley, D. J., Godfrey-Smith, D. I. and Thewalt, M. L. W. (1985) Optical dating of sediments. Nature 313, $105-107$.

Huntley, D. J., Hutton, J. T. and Prescott, J. R. (1993a) The stranded beach-dune sequence of south-east South Australia: a test of thermoluminescence dating, 0-800 ka. Quat. Sci. Rev. 12, 1-20.

Huntley, D. J., Hutton, J. T. and Prescott, J. R. (1993b) Optical dating using inclusions within quartz grains. Geology 21, 1087-1090.

Huntley, D. J., Hutton, J. T. and Prescott, J. R. (1994) Further thermoluminescence dates from the dune sequence in the south-east of South Australia. Quat. Sci. Rev. 13, 201-207.

Huntley, D. J., Berger, G. W., Divigalpitiya, W. M. R. and Brown, T. A. (1983) Thermoluminescence dating of sediments. PACT 9, 607-618.

Hütt, G., Jaek, I. and Tchonka, J. (1988) Optical dating: K-feldspars optical response stimulation spectra. Quat. Sci. Rev. 7, 381-385.

Hütt, G. and Jungner, H. (1992) Optical and TL dating on glaciofluvial sediments. Quat. Sci. Rev. 11, 161163 .

Hütt, G., Jungner, H., Kujansuu, R. and Saarnisto, M. (1993) OSL and TL dating of buried podsols and overlying sands in OstroBothnia, western Finland. J. Quat. Sci. 8, 125-132.

Hutton, J. T., Prescott, J. R., Bowman, J. R., Dunham, M. N., Crone, A. J., Machette, M. N. and Twidale, C. R. (1994) Thermoluminescence dating of Australian palaeoearthquakes. Quat. Sci. Rev. 13, $143-148$.

Huxtable, J. and Aitken, M. J. (1977) Thermoluminescence dating of Lake Mungo geomagnetic polarity excursion. Nature 265, 40-41.

Ikeya, M., Miki, T. and Tanaka, K. (1982) Dating of fault by electron spin resonance on intrafault materials. Science 215, 1392-1393.

Juvigne, E. H. and Wintle, A. G. (1988) A new chronostratigraphy of the late Weichselian loess units in Middle Europe based on thermoluminescence dating. Eiszeitalter und Gegenwart 38, 94-105.

Juyal N., Glennie K. W. and Singhvi A. K. (1997) Chronology and paleoenvironmental significance of 
Quaternary desert sediment in S.E. Arabia. In: Quaternary Deserts and Climate Change (eds Alsharan, A. S. and Glennie, K. W.) Balkema, Cape Town (in press).

Kanemaki, M., Ninagawa, K., Yamamoto, I., Nakagawa, M., Wada, T., Yamashita, Y. and Endo, K. (1991) Red thermoluminescence of volcanic glass fractions from tephras. Nucl. Tracks Radiat. Meas. 18, 81-88.

Krause, W. E., Krbetschek, M. R. and Stolz, W. (1997) Dating of Quaternary sediments from the Schirmacher Oasis (east Antarctica) by infrared stimulated luminescence (IRSL) detected at wavelengths in the region of $560 \mathrm{~nm}$. Quat. Sci. Rev. (Quat. Geochron.) 16, 387-392.

Krbetschek, M. R., Rieser, U., Zöller, L. and Heinicke, J. (1994) Radioactive disequilibrium in palaeodosimetric dating of sediments. Radiat. Meas. 23, 485489.

Kukla G. J. (1987) Correlation of Chinese, European and American loess series with deep-sea sediments. In: Aspects of Loess Research (ed. Liu Tungsheng), pp. 27-38. China Ocean Press, Beijing.

Laj, C., Mazaud, A. and Duplessy, J.-C. (1996) Geomagnetic intensity and ${ }^{14} \mathrm{C}$ abundance in the atmosphere and ocean during the past $50 \mathrm{ky}$. Geophys. Res. Lett. 23, 2045-2048.

Lang, A. (1994) Infra-red stimulated luminescence dating of Holocene reworked silty sediments. Quat. Geochron. (Quat. Sci. Rev.) 13, 525-528.

Lang, A. and Wagner, G. A. (1997) Infrared stimulated luminescence dating of Holocene colluvial sediments using the $410 \mathrm{~nm}$ emission. Quat. Sci. Rev. (Quat. Geochron.) 16, 393-396.

Lian, O. B., Jinsheng, Hu, Huntley, D. J. and Hicock, S. R. (1995) Optical dating studies of Quaternary organic-rich sediments from southwestern British Columbia and northwest Washington State. Can. J. Earth Sci. 32, 1194-1207.

Liritzis, I., Michael, C. and Galloway, R. B. (1996) A significant Aegean volcanic eruption during the second millenium B.C. revealed by thermoluminescence dating. Geoarchaeology 11, 361-371.

Liu Tungsheng (1985) Foreword. In: Loess and the Environment (eds Tungsheng et al. [sic]), p. vi. China Ocean Press, Beijing.

Liu Tungsheng (1987) Aspects of Loess Research Parts I and II. China Ocean Press, Beijing.

Liu Tungsheng and Yuan Baoyin (1987) Palaeoclimate cycles in northern China: Luochuan loess section and its environmental implications. In: Aspects of Loess Research (ed. Liu Tungsheng), pp. 3-26. China Ocean Press, Beijing.

Lundqvist, J. and Mejdahl, V. (1987) Thermoluminescence dating of eolian sediments in central Sweden. Geologiska Föreningens $i$ Stockholm Förhandlingar 109, 147-158.

Lundqvist, J. and Mejdahl, V. (1995) Luminescence dating of the deglaciation in northern Sweden. Quat. Int. 28, 193-197.

McCalpin J. (1986) Thermoluminescence (TL) dating in seismic hazard evaluation: An example from the Bonneville Basin, Utah. In: Proc. 22nd Symposium on Engineering Geology and Soils Engineering (ed. Wood, S. H.), pp. 156-176. Boise, Idaho.

May R. J. and Machette M. N. (1984) Thermoluminescence Dating of Soil Carbonate. United States Department of the Interior, Geological Survey. Report 84-083.

Mejdahl, V. and Funder, S. (1994) Luminescence dating of Late Quaternary sediments from East Greenland. Boreas 23, 525-535.

Miallier, D., Sanzelle, S., Falguères, C., Faïn, J., Pilleyre, T. and Vincent, P. M. (1997) TL and ESR of quartz from the astrobleme of Aorounga (Sahara of Chad). Quat. Sci. Rev. (Quat. Geochron.) 16, 265-274.

Murray, A. S. (1996) Developments in optically stimulated luminescence and photo-transferred luminescence dating of young sediments: Application to a 2000 year old sequence of flood deposits. Geochim. Cosmochim. Acta 60, 565-576.

Murray-Wallace, C. V., Belperio, A. P., Cann, J. H., Huntley, D. J. and Prescott, J. R. (1997) Late Quaternary uplift history, Mount Gambier region, south Australia. Z. Geomorph. N.F. Suppl.-Bd 106, 41-56.

Murton, J. B., French, H. M. and Lamothe, M. (1997) Late Wisconsinan erosion and eolian deposition, Summer Island area, Pleistocene Mackenzie Delta, N.W.T.: optical dating and implications for glacial chronology. Can. J. Earth Sci. 34, 190-199.

Musson, F. M., Clarke, M. L. and Wintle, A. G. (1994) Luminescence dating of loess from the Liujiapo section, central China. Quat. Geochron. (Quat. Sci. Rev.) 13, 407-410.

Nanson, G. C. and Young, R. W. (1987) Comparison of thermoluminescence and radiocarbon age - determinations from late-Pleistocene alluvial deposits near Sydney, Australia. Quat. Res. 27, 263-269.

Nanson, G. C., Price, D. M., Short, S. A., Young, R. W. and Jones, B. G. (1991) Comparative uraniumthorium and thermoluminescence dating of weathered Quaternary alluvium in the tropics of Northern Australia. Quat. Res. 35, 347-366.

Nanson, G. C., Price, D. M. and Short, S. A. (1992) Wetting and drying of Australia over the past 300 ka. Geology 20, 791-794.

Nanson, G. C., Chen, X. Y. and Price, D. M. (1995) Aeolian and fluvial evidence of changing climate and wind patterns during the past $100 \mathrm{ka}$ in the western Simpson Desert, Australia. Palaeogeogr., Palaeoclimatol., Palaeoecol. 113, 87-102.

Nott, J., Young, R., Bryant, E. and Price, D. (1994) Stratigraphy vs. pedogenesis: problems of their correlation within coastal sedimentary facies. Catena 23, 199-212.

Ollerhead, J., Huntley, D. J. and Berger, G. W. (1994) Luminescence dating of sediments from Buctouche Spit, New Brunswick. Can. J. Earth Sci. 31, 523-531.

Olley, J. M., Murray, A. and Roberts, R. G. (1996) The effects of disequilibria in the uranium and thorium decay chains on burial dose rates in fluvial sediments. Quat. Sci. Rev. 15, 751-760.

Page, K., Nanson, G. and Price, D. (1996) Chronology of Murrumbidgee River palaeochannels on the Riverine Plain, south-eastern Australia. J. Quat. Sci. 11, 311326.

Paton T. R., Humphreys G. S. and Mitchell P. B. (1995) Soils. A New Global View, Ch. 3. University College Press, London.

Pillans, B., Kohn, B. P., Berger, G., Froggatt, P., Duller, G., Alloway, B. and Hesse, P. (1996) Multi-method dating comparison for mid-Pleistocene Rangitawa tephra, New Zealand. Quat. Sci. Rev. (Quat. Geochron.) 15, 641-653.

Pilleyre, Th., Montret, M., Faïn, J., Miallier, D. and Sanzelle, S. (1992) Attempts at dating ancient volcanoes using the red TL of quartz. Quat. Sci. Rev. 11, $13-17$.

Porat, N., Wintle, A. G., Amit, R. and Enzel, Y. (1996) Late Quaternary earthquake chronology from luminescence dating of colluvial and alluvial deposits on the Arava Valley, Israel. Quat. Res. 46, 107-117.

Prescott, J. R. and Hutton, J. T. (1995) Environmental dose rates and radioactive disequilibrium from some Australian luminescence dating sites. Quat. Sci. Rev. (Quat. Geochron.) 14, 439-448. 
Prescott, J. R., Huntley, D. J. and Hutton, J. T. (1993) Estimation of equivalent dose in luminescence dating - the Australian slide method. Ancient TL 11, 1-5.

Price, D. M. (1994) TL signatures of quartz grains of different origin. Radiat. Meas. 23, 413-417.

Pye, K., Stokes, S. and Neal, A. (1995) Optical dating of aeolian sediments from the Sefton coast, northwest England. Proc. Geol. Assoc. 106, 281-292.

Readhead M. L. (1982) Extending thermoluminescence dating to geological sediments. In: Archaeometry: an Australasian Perspective (eds Ambrose, W. and Duerdin, P.), pp. 276-281. Australian National University, Canberra.

Readhead, M. L. (1987) Thermoluminescence dose rate data and dating equations for the case of disequilibrium in the decay series. Nucl. Tracks Radiat. Meas. 13, 197-207.

Readhead, M. L. (1988) Thermoluminescence dating of quartz in aeolian sediments from southeastern Australia. Quat. Sci. Rev. 7, 257-264.

Rendell, H. M., Lancaster, N. and Tchakerian, V. P. (1994) Luminescence dating of late Quaternary aeolian deposits at Dale Lake and Cromese Mountains, Mojave Desert, California. Quat. Geochron. (Quat. Sci. Rev.) 13, 417-422.

Rhodes, E. J. and Pownall, L. (1994) Zeroing of the OSL signal in quartz from young glaciofluvial sediments. Radiat. Meas. 23, 581-585.

Richardson, C. A., McDonald, E. V. and Busacca, A. J. (1997) Luminescence dating of loess from the Northwest United States. Quat. Sci. Rev. (Quat. Geochron.) 16, 403-415.

Roberts, R. G., Jones, R. and Smith, M. A. (1990) Thermoluminescence dating of a 50,000-year-old human occupation site in northern Australia. Nature 345, 153-156.

Roberts, R. G., Jones, R., Spooner, N. A., Head, M. J., Murray, A. S. and Smith, M. A. (1994) The human colonisation of Australia: optical dates of 53,000 and 60,000 years bracket human arrival at Deaf Adder Gorge, Northern territory. Quat. Geochron. (Quat. Sci. Rev.) 13, 575-584.

Robertson, G. B., Prescott, J. R. and Hutton, J. T. (1991) Bleaching of the thermoluminescence of feldspars by sunlight. Nucl. Tracks Radiat. Meas. 18, 101-110.

Robertson, G. B., Prescott, J. R. and Hutton, J. T. (1993) Bleaching of the thermoluminescence of feldspars by selected wavelengths present in sunlight. Nucl. Tracks Radiat. Meas. 21, 245-251.

Robertson, G. B., Prescott, J. R. and Hutton, J. T. (1996) Thermoluminescence dating of volcanic activity at Mount Gambier, South Australia. Trans. R. Soc. S. Australia 120, 7-12.

Sankaran, A. V., Nambi, K. S. V. and Sunta, C. M. (1985) Thermoluminescence of laterites, applicability in dating. Nucl. Tracks 10, 177-183.

Schwarcz, H. P. (1994) Current challenges to ESR dating. Quat. Geochron. (Quat. Sci. Rev.) 13, 601-605.

Selsing, L. and Mejdahl, V. (1994) Aeolian stratigraphy and thermoluminescence dating of sediments of late Holocene age from Sola, southwest Norway. Boreas 23, 92-104

Shackleton, N. J., Berger, A. and Peltier, W. R. (1990) An alternative astronomical calibration of the lower Pleistocene based on ODP site 677. Trans. R. Soc. Edinburgh: Earth Sci. 81, 251-261.

Shelkoplyas V. N. and Morozov G. V. (1965) Determination of the relative age of Quaternary deposits of the middle Dnieper by the thermoluminescence method. In: Survey of Problems in the Study of the Quaternary Period. Nauka, Moscow (in Russian, translation of title by JRP).
Shepherd, M. J. and Price, D. M. (1990) Thermoluminescence dating of late Quaternary dune sand, Manawatu/Horowhenua, New Zealand: a comparison with ${ }^{14} \mathrm{C}$ determinations. New Zealand J. Geol. Geogr. 33, 535-539.

Sherwood, J., Barbetti, M., Ditchburn, R., Kimber, R. W. L., McCabe, W., Murray-Wallace, C. V., Prescott, J. R. and Whitehead, N. (1994) A comparative study of Quaternary dating techniques applied to sedimentary deposits in southwest Victoria, Australia. Quat. Geochron. (Quat. Sci. Rev.) 13, 95-110.

Singhvi, A. K., Banerjee, D., Pande, K., Gogte, V. and Valdiya, K. S. (1994) Luminescence studies on neotectonic events in south-central Kumaun Himalaya a feasibility study. Quat. Geochron. (Quat. Sci. Rev.) 13, 595-600.

Singhvi, A. K., Banerjee, D., Ramesh, R., Rajaguru, S. N. and Gogte, V. (1996) A luminescence method for dating "dirty" pedogenic carbonates for paleoenvironmental reconstruction. Earth Planet. Sci. Lett. 139, 321-332.

Smith, B. W. and Prescott, J. R. (1987) Thermoluminescence dating of the eruption of Mt. Schank, South Australia. Aust. J. Earth Sci. 34, 335-342.

Smith, B. W., Rhodes, E. J., Stokes, S., Spooner, N. A. and Aitken, M. J. (1990) Optical dating of sediments: initial quartz results from Oxford Archaeometry 32, 19-31.

Smith, M. A., Prescott, J. R. and Head, M. J. (1997) Comparison of ${ }^{14} \mathrm{C}$ and luminescence chronologies at the Puritjarra Rock shelter, Central Australia. Quat. Sci. Rev. (Ouat. Geochron.) 16, 299-320.

Spell, T. L. and McDougall, I. (1992) Revisions to the age of the Brunhes-Matuyama boundary and the Pleistocene geomagnetic polarity timescale. Geophys. Res. Lett. 19, 1181-1184.

Spooner, N. A. (1992) Optical dating: preliminary results on the anomalous fading of luminescence from feldspars. Quat. Sci. Rev. 11, 139-145.

Spooner N. A. (1993) The validity of optical dating based on feldspars. D. Phil. thesis, Oxford University.

Spooner, N. A. (1994) The anomalous fading of infra-red stimulated luminescence from feldspars. Radiat. Meas. 23, 625-632.

Stokes, S. and Gaylord, D. R. (1993) Optical dating of Holocene dune sands in the Ferris dune field, Wyoming. Quat. Res. 39, 274-281.

Stokes S. and Horrocks J. L. (1997) A reconnaissance survey of the linear dunes and loess plains of Northwestern Nigeria: Granulometry and Geochronology. In: Quaternary Deserts and Climate Change (eds Alsharan, A. S. and Glennie, K. W.) Balkema, Cape Town (in press).

Stokes S., Haynes G., Thomas D. S. G., Horrocks J. L., Higginson M. and Malifa M. (1997) Punctuated aridity in southern Africa during the last glacial cycle: The chronology of linear dune construction in the northeast Kalahari. Palaeogeogr., Palaeoclimatol., Palaeoecol (in press)

Stuiver, M. and Reimer, P. J. (1993) Extended ${ }^{14} \mathrm{C}$ data base and revised CALIB radiocarbon age calibration program. Radiocarbon 35, 215-230.

Sutton, S. R. (1985a) Thermoluminescence measurements on shock-metamorphosed sandstone and dolomite from Meteor Crater, Arizona 1. Shock dependence on thermoluminescence properties. J. Geophys. Res. 90, 3683-3689.

Sutton, S. R. (1985b) Thermoluminescence measurements on shock-metamorphosed sandstone and dolomite from Meteor Crater, Arizona 2. Thermoluminescence age of Meteor Crater. J. Geophys. Res. 90, 36903700 . 
Taylor, R. E., Stuiver, M. and Reimer, P. J. (1996) Development and extension of the calibration of the radiocarbon time scale: archaeological applications. Quat. Sci. Rev. (Quat. Geochron.) 15, 655-668.

Visocekas, R. and Zink, A. (1995) Tunneling afterglow and point defects in feldspars. Radiat. Eff. Def. Solids 134, 265-272.

Visocekas, R., Spooner, N. A., Zink, A. and Blanc, P. (1994) Tunnel afterglow, fading and infrared emissions in thermoluminescence of feldspars. Radiat. Meas. 23, 377-385.

Williams, M. A. G. (1968) Termites and soil development near Brocks Creek, Northern Territory. Aust. J. Sci. 31, 153-154.

Williams, D. F., Thunell, R. C., Tappa, E., Rio, D. and Raffi, I. (1988) Chronology of the Pleistocene oxygen isotope record: $0-1.88$ m.y. B.P.. Palaeogeogr., Palaeoclimatol., Palaeoecol. 64, 221-240.

Wintle, A. G. (1980) A thermoluminescence study of Quaternary calcite: potential and problems. Can. J. Earth Sci. 15, 1977-1986.

Wintle, A. G. (1987) Thermoluminescence dating of loess at Rocourt, Belgium. Geologie en Mijnbouw 66, 3542.

Wintle, A. G. (1990) A review of current research on TL dating of loess. Quat. Sci. Rev. 9, 385-397.

Wintle A. G. (1993) Luminescence dating of aeolian sands: an overview. In: The Dynamics and Environmental Context of Aeolian Sedimentary Systems (ed. Pye, K.), Geol. Soc. Spec. Publ. 72, 4958 .

Wintle, A. G. (1994) Infrared-stimulated luminescence dating of sediments. Radiat. Meas. 23, 607-612.

Wintle, A. G. and Catt, J. A. (1985) Luminescence dating of Dimlington Stadial deposits in eastern England. Boreas 14, 231-234.

Wintle, A. G. and Huntley, D. J. (1979) Thermoluminescence dating of deep sea sediments. Nature 279, $710-712$.

Wintle, A. G. and Huntley, D. J. (1980) Thermoluminescence dating of ocean sediments. Can. J. Earth Sci. 17, 348-360.

Wintle, A. G. and Huntley, D. J. (1982) Thermoluminescence dating of sediments. Quat. Sci. Rev. 1, 31-53.

Wintle, A. G. and Packman, S. C. (1988) Thermoluminescence ages for three sections in Hungary. Quat. Sci. Rev. 7, 315-320.

Wintle, A. G., Li, S. H. and Botha, G. A. (1993) Luminescence dating of colluvial deposits from Natal, South Africa. S. African J Sci. 89, 77-82.

Wintle, A. G., Lancaster, N. and Edwards, S. R. (1994) Infrared stimulated luminescence (IRSL) dating of late-Holocene aeolian sands in the Mojave Desert, California, USA. The Holocene 4, 74-78.

Wintle, A. G., Li, S. H., Botha, G. A. and Vogel, J. C. (1995) Evaluation of luminescence-dating procedures applied to late-Holocene colluvium near St Paul's Mission, Natal, South Africa. The Holocene 5, 97-102.

Wolfe S. A., Huntley D. J. and Ollerhead J. (1995) Recent and late Holocene sand dune activity in southwestern Saskatchewan. In: Current Research 1995-B. pp. 131140. Geol. Survey Canada.

Wood, P. B. (1994) Optically stimulated luminescence dating of a late Quaternary shoreline deposit, Tunisia. Quat. Geochron. (Quat. Sci. Rev.) 13, 513-516.

Zhou, L. P., Dodonov, A. E. and Shackleton, N. J. (1995) Thermoluminescence dating of the Orkutsay loess section in Tashkent region, Uzbekistan, Central Asia. Quat. Sci. Rev. 14, 721-730.

Zink, A. J. C. and Visocekas, R. (1997) Datability of sanidine feldspars using the near-infrared TL emission. Radiat. Meas. 27, 251-261.

Zöller, L. and Wagner, G. A. (1989) Thermoluminescence dating as applied to paleosols. Quat. Int . 1, 61-64.

Zöller, L., Oches, E. A. and McCoy, W. D. (1994) Towards a revised chronostratigraphy of loess in Austria with respect to key sections in the Czech Republic and in Hungary. Quat. Geochron. (Quat. Sci. Rev.) 13, 465-472.

\section{APPENDIX A}

Review Articles of Various Aspects of The Application of Luminescence Dating to Sediments: 1990 and Later

Aitken M. J. (1992) Optical dating. Quat. Sci. Rev. 11, 127-131.

Aitken M. J. (1994) Optical dating: a non-specialist review. Quat. Geochron. (Quat. Sci. Rev.) 13, 503-508.

Berger G. W. (1994) Thermoluminescence dating of sediments older than $\sim 100$ ka. Quat. Geochron. (Quat. Sci. Rev.) 13, 445-455.

Berger G. W. (1995) Progress in luminescence dating methods for Quaternary sediments. In: Dating Methods for Quaternary Deposits, eds Rutter, N. W. and Catto, N. R., pp. 81-104. Geol. Assoc. Canada. Geotext 2.

Duller G. A. T. (1996b) Recent developments in luminescence dating of Quaternary sediments. Prog. Phys. Geog. 20, 127-145.

Murray A. S. (1996) Developments in optically stimulated luminescence and photo-transferred thermoluminescence dating of young sediments: Application to a 2000 year old sequence of flood deposits. Geochim. Cosmochim. Acta 60 , $565-576$.

Rendell H. M. (1995) Luminescence dating of Quaternary sediments. In: Non-Biostratigraphical Methods of Dating and Correlation, eds Dunay, R. E. and Hailwood, E. A. Geol. Soc. Special Publication 89, 223-235.

Wintle A. G. (1990) A review of current research on TL dating of loess. Quat. Sci. Rev. 9, 385-397.

Wintle A. G. (1993) Luminescence dating of aeolian sands: an overview. In: The Dynamics and Environmental Context of Aeolian Sedimentary Systems, ed. Pye, K. Geol. Soc. London Special Publication 72, 49-58.

Wintle A. G. (1993) Recent developments in optical dating of sediments. Rad. Protec. Dosim. 47, 627-635.

Wintle A. G. (1994) Infrared-stimulated luminescence dating of sediments. Rad. Meas. 23, 607-612.

Zöller L. and Wagner G. A. (1990) Thermoluminescence dating of loess - recent developments. Quat. Internat. 7/8, 119-128.

\section{APPENDIX B}

In Writing This Review We have Found The Following to be Useful as an Introductory Source of Reference on Quaternary Environments

Williams M. A. J., Dunkerley D. L., DeDeckker P., Kershaw A. P. and Stokes T. (1993) Quaternary Environments. Edward Arnold, London. 